\title{
The Mechanosensitive Ion Channel MSL10 Modulates Susceptibility to Pseudomonas syringae in Arabidopsis thaliana
}

\author{
Debarati Basu, ${ }^{1,2}$ Jennette M. Codjoe, ${ }^{1,2}$ Kira M. Veley, ${ }^{1}$ and Elizabeth S. Haswell ${ }^{1,2, \dagger}$ \\ ${ }^{1}$ Department of Biology, Washington University in St. Louis, St. Louis, MO 63130, U.S.A. \\ ${ }^{2}$ NSF Center for Engineering Mechanobiology, Washington University in St. Louis, St. Louis, MO 63130, U.S.A.
}

Accepted 11 November 2021.

\begin{abstract}
Plants sense and respond to molecular signals associated with the presence of pathogens and their virulence factors. Mechanical signals generated during pathogenic invasion may also be important, but their contributions have rarely been studied. Here, we investigate the potential role of a mechanosensitive ion channel, MscS-like (MSL)10, in defense against the bacterial pathogen Pseudomonas syringae in Arabidopsis thaliana. We previously showed that overexpression of MSL10-GFP, phospho-mimetic versions of MSL10, and the gain-of-function allele $m s l 10-3 G$ all produce dwarfing, spontaneous cell death, and the hyperaccumulation of reactive oxygen species. These phenotypes are shared by many autoimmune mutants and are frequently suppressed by growth at high temperature in those lines. We found that the same was true for all three MSL10 hypermorphs. In addition, we show that the SGT1/ RAR1/HSP90 cochaperone complex was required for dwarfing and ectopic cell death, PAD4 and SID2 were partially required, and the immune regulators EDS1 and NDR1 were dispensable. All MSL10 hypermorphs exhibited reduced susceptibility to infection by $P$. syringae strain Pto DC3000 and Pto DC3000 expressing the avirulence genes avrRpt2 or avrRpm1 but not Pto DC3000 $h r p L$ and showed an accelerated induction of $P R I$ expression compared with wild-type plants. Null msl10-1 mutants were delayed in $P R 1$ induction and displayed modest susceptibility to infection by coronatine-deficient $P$. syringae pv. tomato. Finally, stomatal closure was reduced in msl10-1 loss-of-function mutants in response to $P$. syringae pv. tomato $\mathrm{COR}^{-}$. These data show that MSL10 modulates pathogen responses and begin to address the possibility that mechanical signals are exploited by the plant for pathogen perception.
\end{abstract}

${ }^{\dagger}$ Corresponding author: E. S. Haswell; ehaswell@wustl.edu

Current address for Debarati Basu: Dept. of Biology, Louisiana State University, Baton Rouge, LA 70803, U.S.A.

Current address for Kira M. Veley: Donald Danforth Plant Science Center, St. Louis, MO 63132, U.S.A.

Funding: This work was supported by National Science Foundation grant NSF MCB-1253103 and a Center for Engineering Mechanobiology Award NSF STC CMMI-1548571. J. M. Codjoe was supported by Graduate Research Fellowship NSF DGE-1745038.

*The $e$-Xtra logo stands for "electronic extra" and indicates there are supplementary materials published online.

The author(s) declare no conflict of interest. distributed under the CC BY-NC-ND 4.0 International license.
Keywords: Arabidopsis thaliana, mechanosensitive ion channel, MSL10, Pseudomonas syringae

Plant immune receptors achieve a two-tiered response to pathogens (Chiang and Coaker 2015; Jones et al. 2016; Zhou and Zhang 2020). The first line of defense relies on plasma membranelocalized pattern recognition receptors (PRRs), which facilitate molecular recognition of microbe- or damage-associated molecular patterns (MAMPs or DAMPs, respectively) and subsequently trigger pattern-triggered immunity (PTI) (DeFalco and Zipfel 2021; Saijo et al. 2018). However, pathogens evade PTI responses by delivering molecular virulence factors or effectors that subvert basal defenses into host cells (Toruño et al. 2016; Saur et al. 2021).

To counter such pathogens, plants have, in turn, evolved cytosolic receptors that constitute the second layer of plant defense (Jones et al. 2016). These intracellular receptors contain nucleotidebinding leucine-rich repeats and are thus known as NB-LRRs or NLRs. Both toll interleukin 1 (TIR)-NLR and coiled coil (CC)NLRs detect the presence of intracellular effectors and activate effector-triggered immunity (ETI) (Cui et al. 2015). Some NLRs recognize and bind effectors directly, while others recognize the host proteins that effectors modify (Khan et al. 2018). It has recently been discovered that ZAR1 CC-NLRs oligomerize to form a large complex that serves to detect the activity of several bacterial effectors and is capable of channeling calcium and triggering defense responses (Bi et al. 2021; Wang et al. 2019). The TIRNLRs ROQ1 and RPP1 also oligomerize to form "resistosomes" with nicotinamide dinucleoside hydrolase activity (Ma et al. 2020; Martin et al. 2020).

As described above, the molecular perception of pathogens and their effectors by PRRs and NLRs is central to the plant immune response. However, there is growing evidence that mechanical signals generated during invasion also elicit plant defense responses. For example, Arabidopsis, strawberry, and bean plants acquire transient immunity to necrotic or wounding pathogens following mild mechanical stimulus (Coutand 2020). It is not yet known if pathogens create detectable mechanical perturbations, if the mechanoperception of pathogens utilizes the same pathways as defenses do, nor how such signals would be detected.

One mechanism by which the plant may recognize pathogenassociated mechanical signals is the activation of mechanosensitive (MS) ion channels. Multiple families of MS ion channels mediate the flux of ions across a membrane in response to increased membrane tension in plants (Basu and Haswell 2017; Guerringue et al. 2018). Genetic and biochemical data support roles for several proteins that are homologs of known MS ion channels in the response to pathogens. Plants lacking the AtPIEZO1 channel are unable to fully suppress long-distance movement of viruses (Zhang et al. 2019), and OSCA1.3 is required for immunity-based stomatal 
closure (Thor et al. 2020). MCA family members are also implicated in pathogen signaling and feedback loops (Engelsdorf et al. 2018). The putative MS ion channel MscS-like (MSL) 4 contributes to basal immunity and MAMP-induced responses (Zhang et al. 2017).

MSL10 is a ubiquitously expressed homolog of MSL4 and is known to form a mechanically activated ion channel both in root cells and in Xenopus oocytes (Haswell et al. 2008; Maksaev and Haswell 2012), making it an intriguing candidate for a sensor of pathogen invasion. It is directly activated through membrane tension and is largely nonselective, with a slight preference for anions (Maksaev and Haswell 2012). Based on homology to other MSL channels, the MSL10 channel is likely a homoheptamer (Bass et al. 2002; Deng et al. 2020), though it may form multimeric complexes with its closest homolog, MSL9 (Haswell et al. 2008).

Plants constitutively overexpressing MSL10-GFP (green fluorescent protein) display severe growth retardation, hyperaccumulation of $\mathrm{H}_{2} \mathrm{O}_{2}$, induction of genes associated with stress response and ectopic cell death (Basu et al. 2020; Veley et al. 2014). These phenotypes are reproduced in plants harboring an ethylmethane sulphonate-induced gain-of-function point mutation in the soluble $\mathrm{C}$ terminus (S640L; msllo-3G) and in transgenic lines expressing an untagged version of MSL10 containing seven Ser/Thr-to-Ala mutations in the soluble $\mathrm{N}$ terminus from the native (or genomic) context $\left(M S L 10 g^{7 A}\right.$ ) (Basu et al. 2020). Plants expressing wild-type (WT) MSL10 (MSL10g) or a phospho-mimetic version of MSL10 (MSL10g $\left.{ }^{7 D}\right)$, do not share these phenotypes, suggesting that dephosphorylation of $\mathrm{N}$-terminal Ser/Thr residues leads to channel activation (Basu et al. 2020). Because MSL10-GFP overexpressors, msl10-3G mutants, and plants expressing MSL $10 g^{7 A}$ all show the same gain-of-function phenotypes, we collectively refer to them here as MSL10 hypermorphs. While the molecular mechanism by which MSL10 hypermorphs are dysregulated has not yet been established, we have speculated that phosphorylation of the seven Ser/Thr residues in the MSL10 N terminus keeps it in an inactive signaling state and that either preventing phosphorylation with Ser/Thr-to-Ala mutations or overexpression of the GFP-tagged protein circumvents this regulation (Basu et al. 2020; Veley et al. 2014). We also recently proposed that an interaction between the soluble $\mathrm{N}$ and $\mathrm{C}$ termini of MSL10 monomers accompanies MSL10 activation and that the msl10-3G point mutation promotes or recapitulates this activation (Basu et al. 2020).

Dwarfism and spontaneous lesions are also observed in two previously characterized, partially overlapping classes of Arabidopsis thaliana mutants. Autoimmune mutants are unable to properly suppress immune responses in the absence of pathogens (van Wersch et al. 2016), while lesion mimic mutants (LMMs) exhibit uncontrolled programmed cell death on the leaf surface (Bruggeman et al. 2015). Prompted by these similarities between autoimmune and LMMs and MSL10 hypermorphs, our previous characterizations of MSL10 as a sensor of membrane tension, and by the intriguing possibility that plants could sense mechanical signals of pathogen invasion, we investigated the potential role of MSL10 in plant defense responses against Pseudomonas syringae.

\section{RESULTS}

Growth at high temperatures suppresses the phenotypes associated with overexpression of MSL10-GFP, expression of $\mathrm{MSL10} \mathrm{g}^{7 \mathrm{~A}}$, and the msl10-3G mutant.

Growth at elevated temperatures $\left(28\right.$ to $\left.30^{\circ} \mathrm{C}\right)$ can suppress the dwarfing and the localized ectopic cell death in autoimmune mutants (Hammoudi et al. 2018; Hua 2013; Huot et al. 2017), and we speculated that the same might be true for MSL1O hypermorphs. As shown previously (Veley et al. 2014), MSL10GFP overexpressors were dramatically smaller than the WT when grown at $21^{\circ} \mathrm{C}$ (Fig. 1A and B). However, when grown at high temperature, MSL10-GFP overexpressing lines were nearly indistinguishable from WT, msl10-1, or msl9-1 msl10-1 mutant plants in terms of rosette size and fresh weight. Elevated temperature did not substantially alter the level of transcripts from the endogenous MSL10 gene in WT plants, msl10-1 null mutants, or MSL10-GFP overexpression lines (Fig. 1C), and MSL10-GFP protein abundance was unaffected (Fig. 1D). Furthermore, MSL10-GFP was localized at the periphery of the cell at both normal and high temperatures in all three transgenic lines (Fig. 1E). Growth at high temperature also suppressed dwarfing in $m s l 10-3 G$ mutants and in plants expressing the MSL10g ${ }^{7 A}$ transgene but did not affect the growth of plants expressing MSL10g or $M S L 10 g^{7 D}$. High temperature did not appreciably affect transcript levels of endogenous or transgenic MSL10 in these lines (Supplementary Fig. S1). Thus, growth at elevated temperatures relieved dwarfing in all three MSL10 hypermorphs but did not do so by altering transcript levels, protein abundance, or subcellular localization. Growth at elevated temperature also suppressed previously documented cellular phenotypes of MSL10 hypermorphs, including the hyperaccumulation of reactive oxygen species (ROS), ectopic cell death, and increased transcript levels of four genes previously established as hallmarks of MSL10 activity (Veley et al. 2014).

We assessed these phenotypes in rosette leaves from threeweek-old WT and msllo-1 and msllo-3G mutant plants, three independent transgenic lines overexpressing MSL10-GFP (previously described by Veley et al. [2014]), and msl10-1 plants harboring MSL10g, MSL1Og ${ }^{7 A}$, or MSL $10 g^{7 D}$ transgenes (which contain a genomic copy of WT MSL10, MSL10 with seven phospho-dead mutations in the soluble N-terminus, or MSL10 with seven phospho-mimetic mutations in the soluble $\mathrm{N}$ terminus, respectively, all previously described by Basu et al. [2020]). When plants were grown at high temperatures, the increased $\mathrm{O}^{2-}, \mathrm{H}_{2} \mathrm{O}_{2}$, and ectopic cell death observed in MSL10-GFP overexpression lines, the msl10-3G mutant, and $M S L 10 g^{7 A}$ transgenic lines were similar to that found in the WT (Fig. 2A, B, and C). MSL10g and MSL10g ${ }^{7 D}$ lines and msl10-1 mutants were indistinguishable from the WT when grown at high or at normal temperatures. The difference in scale between the data shown in Figure $2 \mathrm{~B}$ and $\mathrm{C}$ can be attributed to different instruments used in analyzing ROS and cell death (discussed below). Finally, the transcript levels of four genes previously identified as reporters of MSL10 overactivation (Basu et al. 2020; Veley et al. 2014) were reduced to almost WT levels when MSL10-GFP overexpressing plants were grown at high temperatures (Fig. 2D). Taken together, these data show that growth at high temperature relieves all the phenotypes associated with the presence of hypermorphic alleles of MSL10. Because similar phenotypes in autoimmune mutants are also suppressed by high temperature (Hua 2013), these results suggested that the MSL10 hypermorph phenotypes might also be derived from the overactivation of immune response pathways.

\section{MSL10-GFP overexpression phenotypes require $S G T 1, R A R 1$, and HSP90.}

To test the hypothesis that MSL10 hypermorphs produce an autoimmune response, we asked if key genes involved in pathogen response were required for MSL10-GFP overexpression phenotypes. Most NLRs require SUPPRESSOR of G2 ALLELE of SKP1 (SGT1) for function (Kadota et al. 2010). SGT1 is part of a cochaperone complex that includes REQUIRED for MLA12 RESISTANCE 1 (RAR1), and HEAT SHOCK PROTEIN 90 kD (HSP90) (Liu et al. 2004; Siligardi et al. 2018; Takahashi et al. 2003). SGT1, RAR1, and HSP90 interact directly with NLRs 
and are required for their accumulation and subcellular trafficking (Borrelli et al. 2018). Thus, in the absence of any known NLR associated with MSL10-induced downstream autoimmune response or any evidence of MSL10 acting as a target for a pathogen effector protein, we tested if silencing of $S G T 1, R A R 1$, and $H S P 90$ by virusinduced gene silencing (VIGS) (Baulcombe 1999) could abolish the cell death triggered by transiently overexpressed MSL10-GFP in Nicotiana benthamiana.
Leaves were agroinfiltrated with VIGS constructs (TRV2:SGT1, TRV2:RAR1, TRV2:HSP90, or empty vector). After 10 days, transcript levels of each target gene were reduced by approximately $80 \%$ (Supplementary Fig. S2A). After another 10 days, leaves were subjected to a second agroinfiltration with $35 S:: M S L 10$ $G F P, 35 S:: M S L 10^{7 D}-G F P$, or $35 S:: M S L 10^{7 A}-G F P$. Cell death was quantified 5 days later, using dual fluorescein diacetate (FDA) propidium iodide (PI) staining as described by Veley et al. (2014). As
A

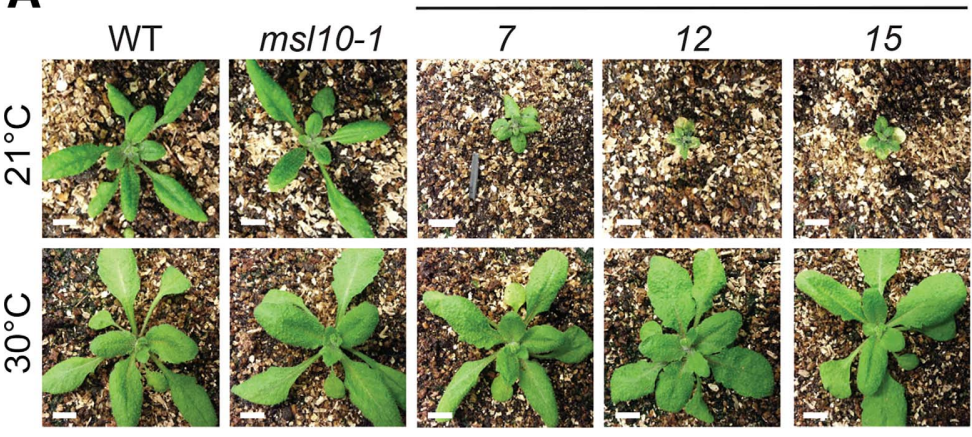

C

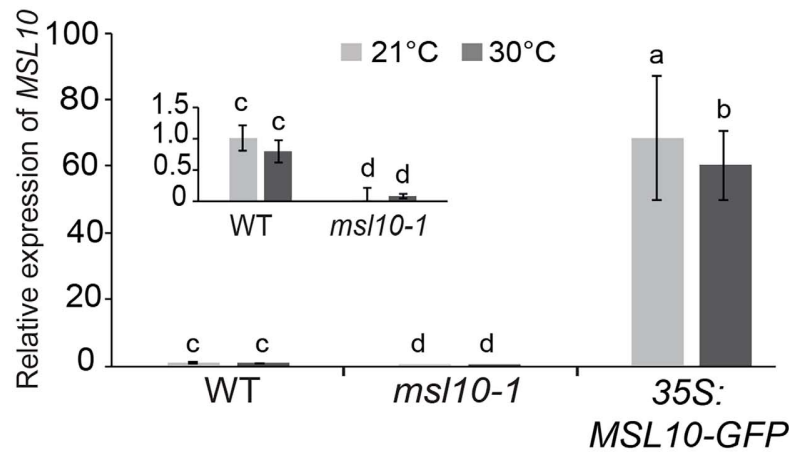

B

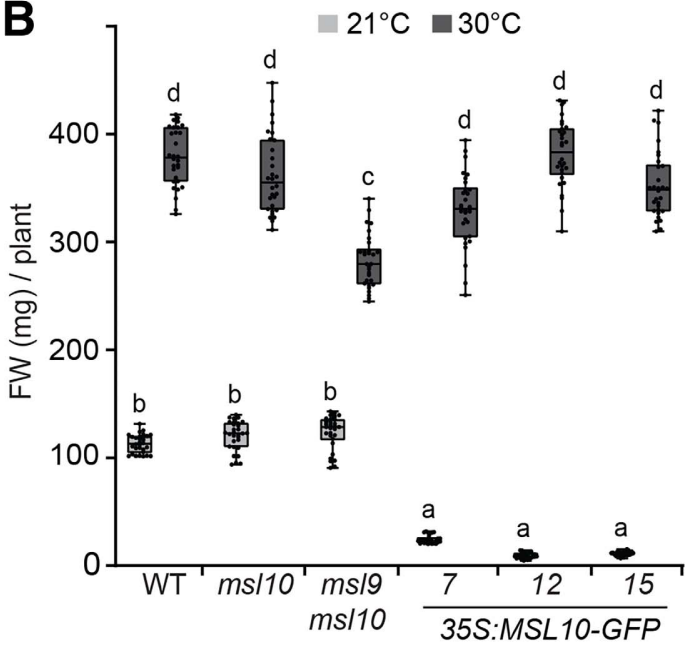

$\mathbf{E}$

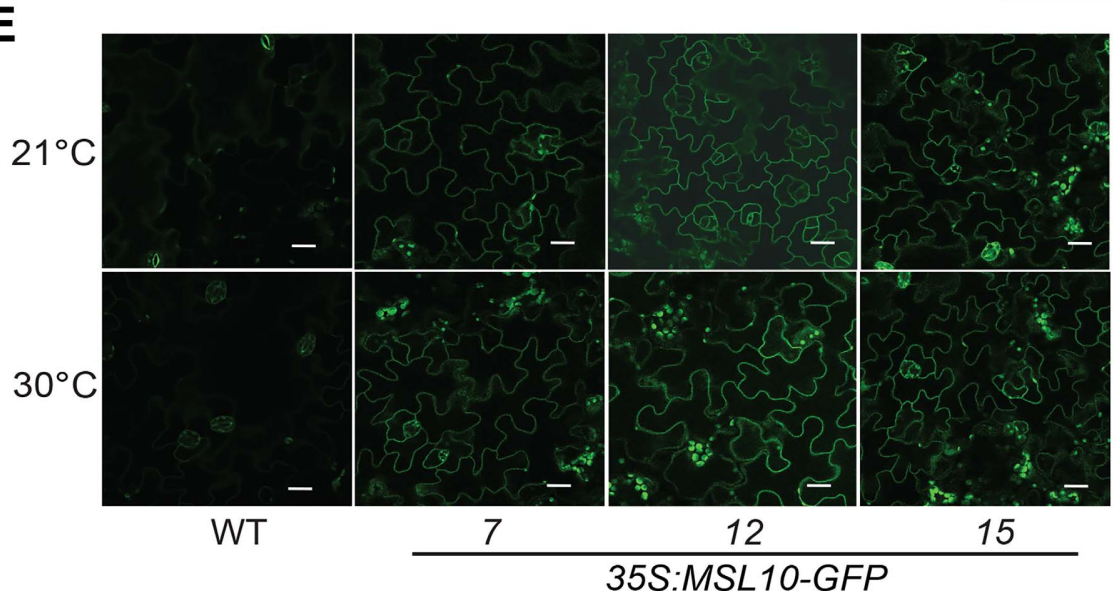

Fig. 1. Growth at high temperatures suppresses dwarfing in MSL10-GFP (green fluorescent protein) overexpressors. A, Three-week-old seedlings from wild type (WT), msl10-1, and three independent T4 homozygous lines overexpressing MSL10-GFP, grown side-by-side on soil under $24 \mathrm{~h}$ of light at 21 or $30^{\circ} \mathrm{C}$. Bars $=0.5 \mathrm{~cm}$. B, Fresh weight $(\mathrm{FW})$ of the aerial portion of plants grown as in A. Error bars indicate standard deviation of the mean FW from 30 plants, grown in three independent trials, 10 plants per trial. C, MSL10 transcript abundance relative to WT in WT, msl10-1, or 35S::MSL10GFP-15 plants, grown as in A. Inset, WT and msl10-1 lines only. Expression levels were normalized to EF1 $\alpha$ and UBQ5. Error bars indicate standard error of the mean from three independent trials, three technical replicates per trial. D, Immunoblot of protein extracts from rosette leaves of two-weekold plants. MSL10-GFP was detected with an anti-GFP primary antibody (top), then, the blot was stripped and reprobed with an anti- $\alpha$ tubulin primary antibody (bottom). The intensity of each MSL10-GFP protein band, normalized to tubulin, is indicated at the bottom of the blot. E, Confocal images of leaf epidermal cells from plants grown as in A. GFP signal is shown in green. All images were obtained using identical settings. Bars $=20 \mu \mathrm{m}$. In B and C, different letters indicate significant differences, as determined by two-way analysis of variance followed by Tukey's post hoc test $(P<0.05)$. 

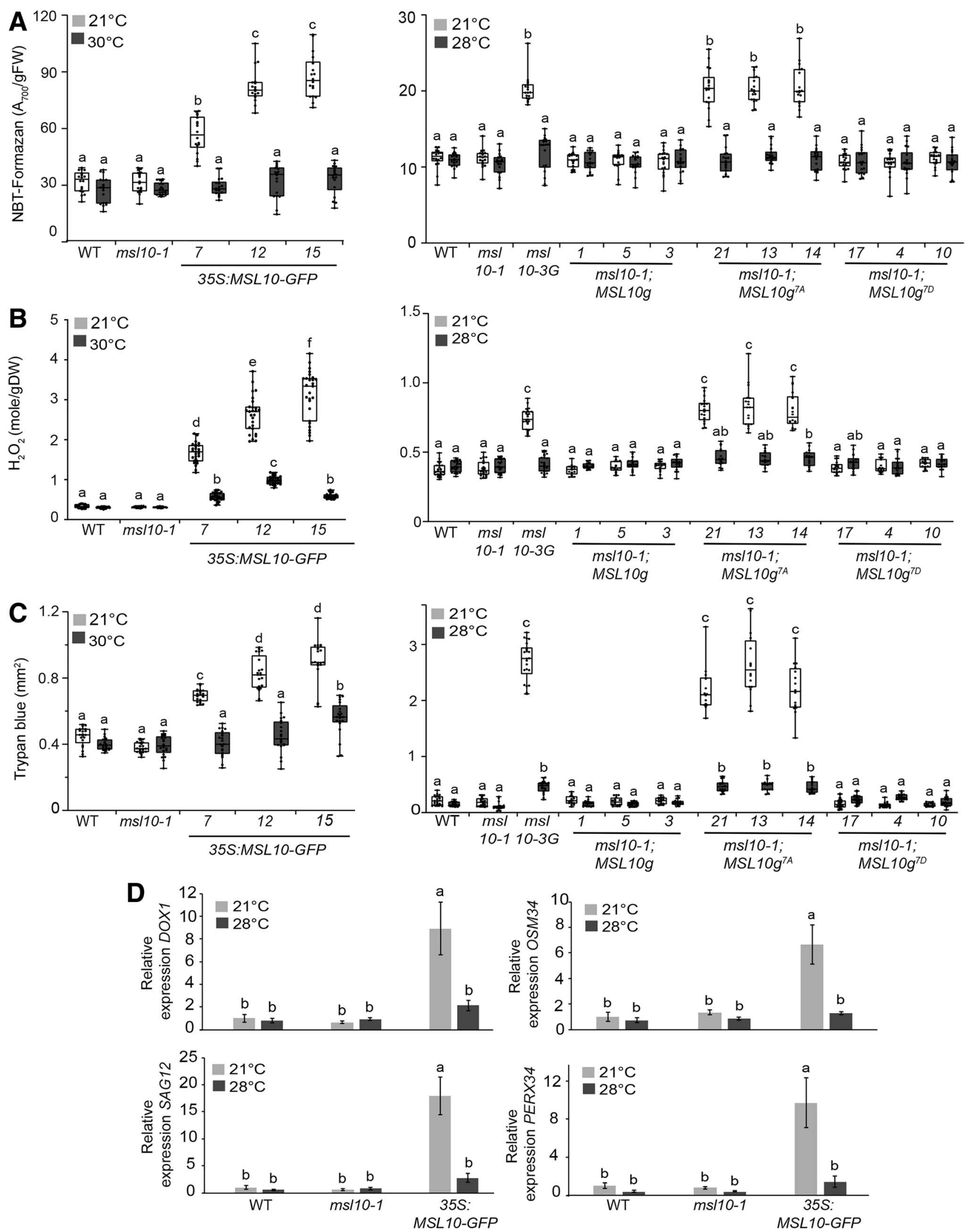

Fig. 2. Growth at high temperatures suppresses multiple cellular and molecular phenotypes associated with MSL10 hypermorphs. A, Colorimetric quantification of superoxide content, as indicated by nitroblue tetrazolium chloride (NBT)-formazan deposition, in rosette leaves in three-week-old plants of the indicated genotypes grown at 21 or $28^{\circ} \mathrm{C}$ under $24 \mathrm{~h}$ of light. B, Hydrogen peroxide $\left(\mathrm{H}_{2} \mathrm{O}_{2}\right)$ content in rosette leaves grown as in A, quantified with the Amplex Red-coupled quantitative assay. C, Ectopic cell death indicated by trypan blue staining in rosette leaves grown as in A. D, Relative transcript abundance of four previously characterized stress-responsive genes. In all panels, different letters indicate significant differences, as determined by twoway analysis of variance followed by Tukey's post hoc test $(P<0.05)$. A to $\mathrm{C}$ present the means \pm standard deviation from three independent trials, five to ten leaves per genotype. 
expected, in leaves that had been pre-infiltrated with an empty VIGS vector, transient expression of WT MSL10-GFP resulted in the death of approximately $27 \%$ of $N$. benthamiana epidermal cells and expression of MSL10 ${ }^{7 \mathrm{~A}}$-GFP triggered even more cell death (approximately 39\%), while expression of MSL10 ${ }^{7 \mathrm{D}}$-GFP resulted in the death of just $11 \%$ of cells (Fig. 3A). However, we found that silencing of either $S G T 1, R A R 1$, or HSP90 almost completely prevented cell death in leaves that were transiently expressing MSL10GFP (approximately 10\%) or MSL10 ${ }^{7 \mathrm{~A}}$-GFP (approximately $16 \%$ ). Immunoblotting showed MSL10-GFP protein levels were not significantly different in silenced and non-silenced samples (Supplementary Fig. S2B to D; Supplementary Table S2). Rather,
A
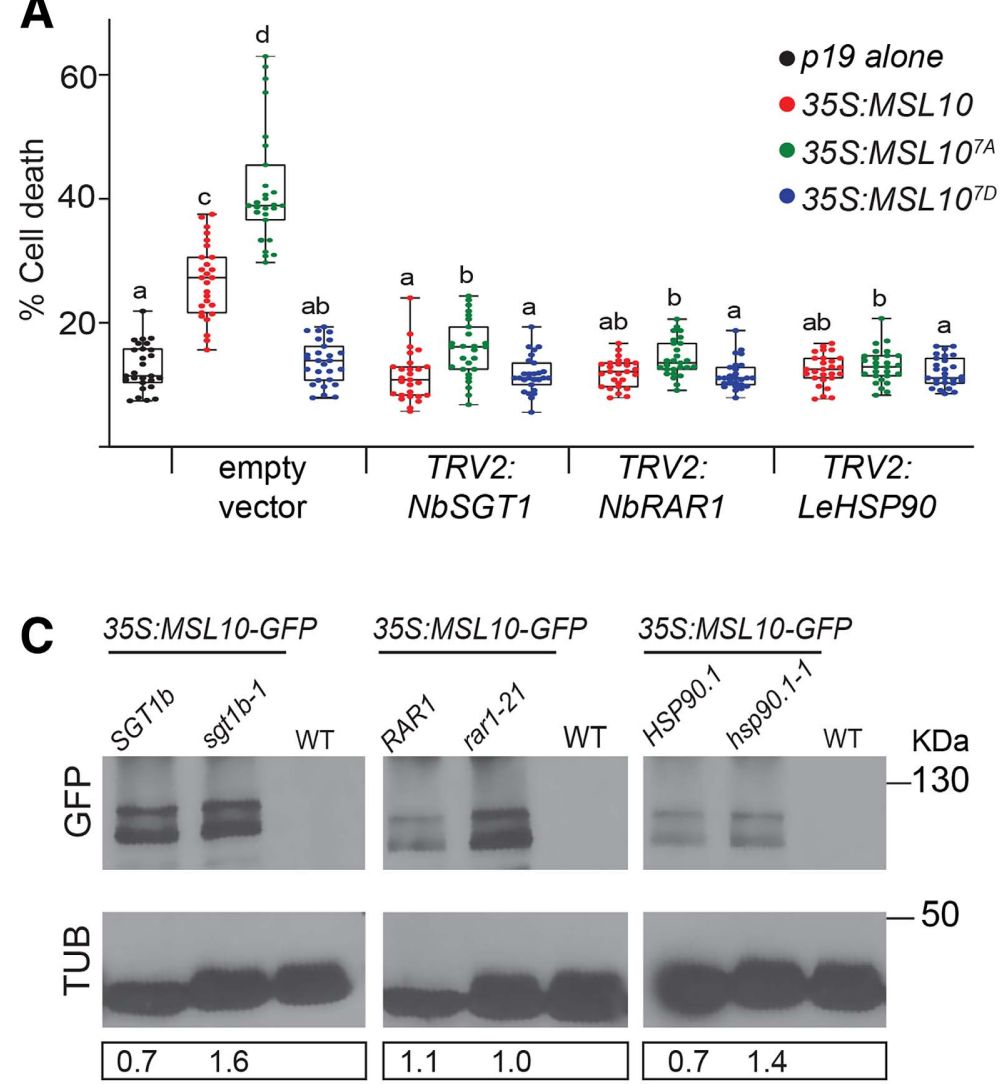

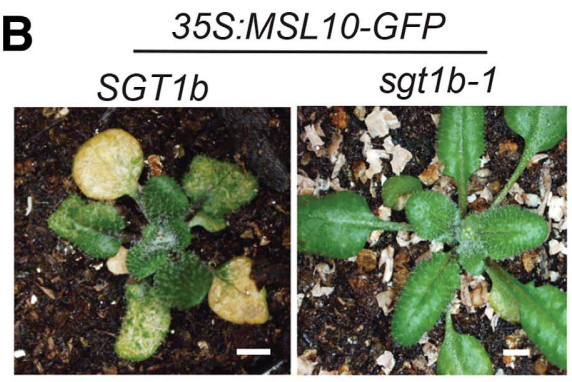

RAR1

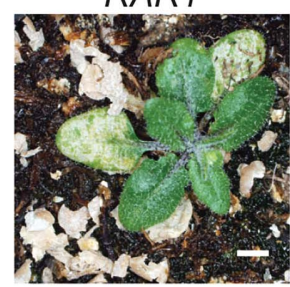

$\operatorname{rar1}-21$

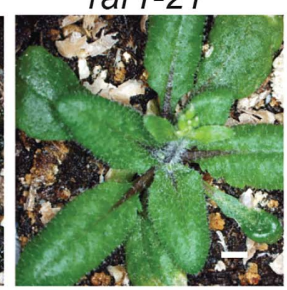

HSP90.1

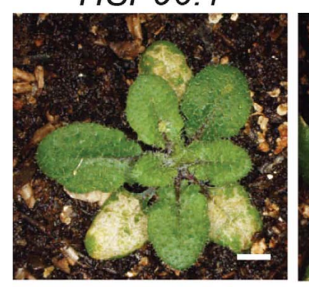

hsp90.1-1

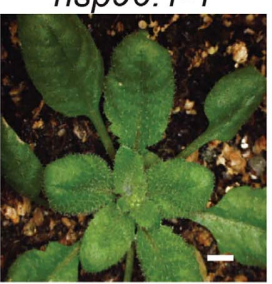

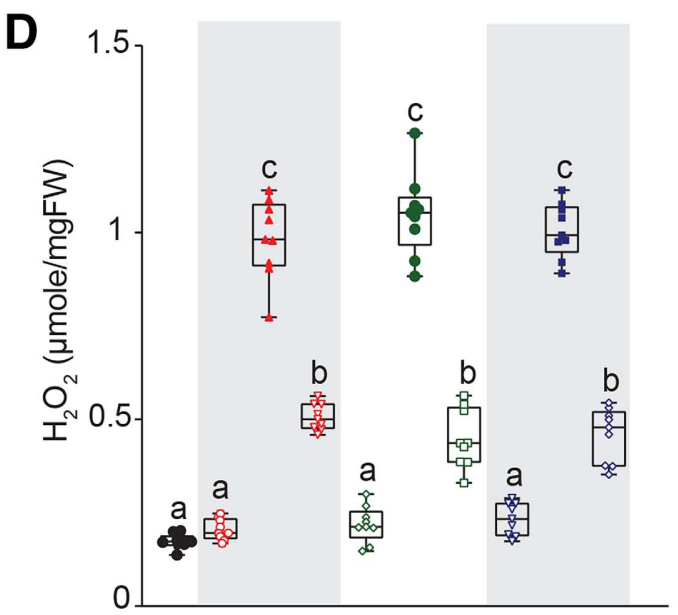

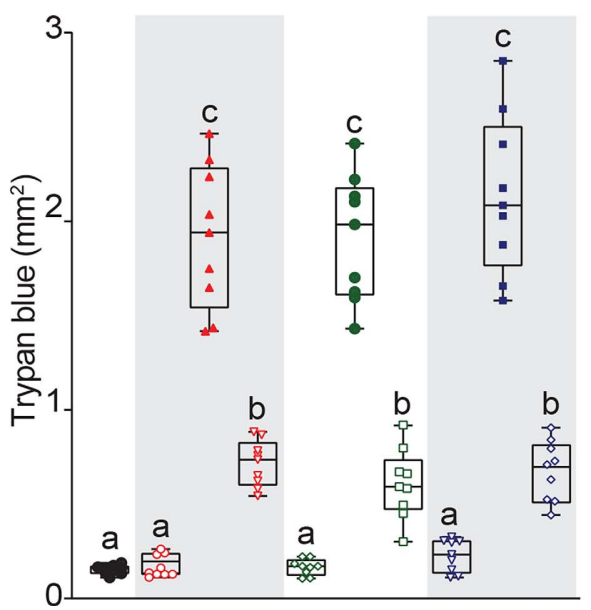

- WT

- $\operatorname{sgt1b-1}$

\ SGT1b 35S:MSL10-GFP

$\nabla$ sgt1b-1 35S:MSL10-GFP

$\diamond \operatorname{rar1}-21$

- RAR1 35S:MSL10-GFP

口 rar1-21 35S:MSL10-GFP

$\nabla h s p 90.1-1$

HSP90.1 35S:MSL10-GFP

$\diamond$ hsp90.1-1 35S:MSL10-GFP

Fig. 3. SGT1b, RAR1, and HSP90 are required for phenotypes associated with MSL10-GFP overexpression in tobacco and Arabidopsis. A, Quantification of cell death, as determined by dual staining fluorescein diacetate and propidium iodide in epidermal cells from Nicotiana benthamiana leaves transiently overexpressing MSL10-GFP and its phospho-variants when SGT1b, RARl, or HSP90 was silenced. The means and standard deviation (SD) from three independent trials are shown. Each datapoint represents the percent cell death from approximately 100 epidermal cells from a single leaf. For each genotype, three leaves each from three different plants were assessed per trial, for a total of three independent trials. B, 35S::MSL10-GFP seedlings segregating sgtlb-1, rarl-21, or hsp90.1-1, grown side-by-side on soil under $24 \mathrm{~h}$ of light at $21^{\circ} \mathrm{C}$. Left panel bars $=0.5 \mathrm{~cm}$; right panel bars $=0.35 \mathrm{~cm}$. $\mathbf{C}$, Immunoblot showing MSL10-GFP levels in total protein extracted from three-week-old rosette leaves grown as in B. Relative MSL10-GFP levels (normalized to tubulin) are shown at the bottom of each lane; replicates and statistics are shown in Supplementary Table S2. D, Hydrogen peroxide (left) and trypan blue (right) content in rosette leaves. The means and SD from three independent trials, each with three leaves are presented. In A and D, different letters indicate significant differences, as determined by two-way analysis of variance followed by Tukey's post hoc test $(P<0.05)$. 
they suggest that $S G T 1, R A R 1$, or HSP90 function downstream of $M S L 10$ and are required for its ability to induce programmed cell death.

We next investigated the same question in Arabidopsis plants stably expressing $35 S:: M S L 10-G F P$ into the T-DNA insertion lines sgtlb-1 (SALK_026606) and hsp90.1-1 (SALK_007614; (Takahashi et al. 2003) and the point mutant rarl-21 (Tornero et al. 2002). The sgtlb-1 mutant line has a T-DNA inserted in the promoter region of the $S G T 1 b$ gene and $S G T 1 b$ expression was reduced to approximately $60 \%$ of that in WT plants (Supplementary Fig. S3A and B), indicating that the sgt $1 b-1$ mutant is a knock-down allele of SGT1b. The sgt1b-1, rarl-21, and hsp90.1 mutants did not exhibit detectable morphological differences compared with WT plants (Supplementary Fig. S3C). To avoid variability in transgene expression due to position effect, we decided to first incorporate a transgene in a mutant background and cross the T1 selected plant with WT Col-0. The segregating F2 progenies of homozygous knock-out mutant and WT (both harboring the transgene integrated in the same location in the chromosome of either genetic background) were considered for further analysis.

As expected, plants expressing $35 S: \because M S L 10-G F P$ in the WT $S G T 1 b, R A R 1$, and HSP90.1 backgrounds exhibited dwarfing and ectopic cell death, as assessed by the appearance of yellowishbrown lesions on rosette leaves. (Fig. 3B). However, these phenotypes were largely absent in MSL10-GFP overexpressing siblings homozygous for sgt1b-1, rarl-21, and hsp90.1-1. Immunoblotting and confocal imaging showed that this loss of cell death could not be attributed to a decrease in MSL10-GFP protein abundance (Fig. 3C; Supplementary Fig. S3D; Supplementary Table S2). $\mathrm{H}_{2} \mathrm{O}_{2}$ hyperaccumulation and ectopic cell death were also markedly reduced in sgt1b-1 35S::MSL10-GFP (approximately 50 and 65\%), rarl-21 35S::MSL10-GFP (approximately 60 and 70\%), and hsp90.1-1 35S::MSL10-GFP (approximately 50 and 67\%) lines compared with their 35S::MSL10-GFP siblings (Fig. 3D). We obtained similar results with a recently described null allele of SGT1b (sgt1b-2, GABI_857A04) (Zhang et al. 2015) (Supplementary Fig. S3E, F, and G). These results collectively indicate that the dwarfing, $\mathrm{H}_{2} \mathrm{O}_{2}$ accumulation, and ectopic cell death associated with MSL10-GFP overexpression require the surveillance complex SGT1/RAR1/HSP90.1 in both $N$. benthamiana and Arabidopsis. However, this effect does not appear to be mediated through protein-protein interactions, as SGT1b, RAR1, and HSP90.1 did not associate with MSL10 in bimolecular fluorescence complementation (BiFC) assays (Supplementary Fig. S4). These data suggest that MSL10 indirectly requires the function of the surveillance complex to induce programmed cell death, likely through converging pathways. However, we cannot rule out the possibility that a combination or even all three of these proteins must be present for MSL10 to interact stably with the SGT1/ RAR1/HSP90.1 complex.

\section{The phenotypes associated with MSL10-GFP overexpression are independent of EDS1 and NDR1.}

Downstream of NLR function, the immune regulator ENHANCED DISEASE SUSCEPTIBILITY (EDS1) is a lipaselike protein that serves to connect TIR-NLR signaling with downstream events, including programmed cell death, production of the defense hormone salicylic acid (SA), and defense gene expression (Dongus and Parker 2021). NON-RACE-SPECIFIC DISEASE RESISTANCE 1 (NDR1), a membrane-associated integrin-like protein, plays a similar role for CC-NLRs (Century et al. 1995, 1997; Coppinger et al. 2004; Knepper et al. 2011). To investigate whether disruption of EDS1 or NDR1 are required for dwarfing or cell death observed in MSL10-GFP overexpression lines or the msl10-3G background, we introduced 35S::MSL10-GFP into the eds1-23 (SALK_057149, (Song 2016) and the ndr1-1 (Century et al. 1997) null mutant backgrounds by transformation. As anticipated, expression of $35 S:: M S L 10-G F P$ in WT plants resulted in severe dwarfing and the appearance of yellowish-brown lesions on rosette leaves (Fig. 4A, top panels) and trypan blue-stained patches on leaves (Fig. 4A, bottom panels) compared with the WT or to untransformed eds1-23 or ndrl-1 mutants. We found that neither the eds 1-23 nor the ndrl-1 mutant background appreciably affected the phenotypic results of MSL10-GFP overexpression, and immunoblotting confirmed similar MSL10-GFP levels in all lines (Fig. 4B). Similarly, neither the eds1-23 nor the $n d r l-1$ alleles altered dwarfing or ectopic cell death observed in the msl10-3G background (Fig. 4C). Collectively, these results indicate that the phenotypes associated with MSL10 hypermorphs are independent of EDSI and NDRI.

\section{$P A D 4$ and SID2 are partially required for the dwarfing and ectopic cell death associated with MSL10-GFP overexpression.}

SA accumulation is often associated with inhibition of growth, spontaneous cell death, and immune responses (Bruggeman et al. 2015; Peng et al. 2021). This prompted us to investigate whether SA biosynthesis might be required for MSL10-associated phenotypes. Toward this goal, we crossed plants expressing 35S::MSL10GFP with PHYTOALEXIN DEFICIENT 4-1 (pad4-1), SA INDUCTION DEFICIENT2-2 (sid2-2) double mutants (Jirage et al. 1999; Wildermuth et al. 2001). The SID2 gene encodes ICS1, a key SA biosynthetic enzyme, while PAD4 is a lipase-like protein that is involved in transcriptional upregulation of SA accumulation $(\mathrm{Ng}$ et al. 2011). We followed the approach described above to assess transgenic siblings with different genetic backgrounds. Four-weekold pad4-1sid2-2 siblings were phenotypically indistinguishable from the WT (PAD4 SID2) parental line, but pad4-1 sid2-2 siblings overexpressing MSL10-GFP displayed partial suppression of the dwarfing and fresh weight seen in the 35S::MSL10-GFP line (Fig. 5A and B). Consistent with these phenotypic features, the level of ectopic cell death in pad4-1sid2-2 35S::MSL10-GFP leaves was approximately $50 \%$ lower than that observed in 35S::MSL10-GFP overexpression lines (Fig. 5C). MSL10-GFP levels were comparable in both types of siblings, as assessed by immunoblotting (Fig. 5D; Supplementary Table S2). These results suggest that SA biosynthesis influences but is not required for the autoimmune phenotypes associated with MSL10-GFP overexpression.

\section{Hypermorphic alleles of MSL10 confer reduced susceptibility to Pseudomonas syringae.}

Pseudomonas syringae is a model for plant-pathogen studies, and programmed cell death is commonly triggered during the hypersensitive response of Arabidopsis to Pseudomonas syringae interactions (Xin and He 2013). Since MSL10 hypermorphs are known to trigger cell death in response to cell swelling (Basu and Haswell 2020) and cell death is a typical immune response, we asked whether MSL10 contributes to pathogen resistance. Plants were grown at $28^{\circ} \mathrm{C}$ under short-day conditions for five to six weeks to suppress the cell death and dwarfing phenotypes of MSL10 hypermorphs prior to infection. Then, since elevated temperature suppresses both plant immunity and pathogen virulence (Huot et al. 2017), five- to six-week-old plants were transferred to $21^{\circ} \mathrm{C} 24 \mathrm{~h}$ before inoculation with bacterial cultures. Using this strategy (Supplementary Fig. S5), the levels of $\mathrm{H}_{2} \mathrm{O}_{2}$ and cell-death plants harboring MSL10 hypermorphic alleles remained indistinguishable from the WT plants at the time of infection, 1 day after transfer to $21^{\circ} \mathrm{C}$.

Fully expanded leaves were syringe-inoculated with Pto DC3000, which is virulent and can multiply to high levels (100to 1,000-fold) in WT Col-0 plants. At the start of the experiment, no differences in bacterial counts were observed among any lines (Fig. 6A). At 3 days postinfection, msl10-3G mutants supported 
significantly lower bacterial growth than WT plants, as did plants overexpressing MSL10-GFP and plants expressing MSL10g ${ }^{7 \mathrm{~A}}$. In contrast, phospho-mimetic versions of MSL10 transgenes (35S::MSL10-GFP $P^{4 D}$ or $M S L 10 g^{7 D}$ ) and the msl10-1 mutant had no apparent effect relative to the WT. The pad4-1sid2-2 mutant, which does not accumulate SA in response to infection, exhibited enhanced susceptibility to Pto DC3000.

The enhanced resistance against Pto DC3000 exhibited in lines expressing MSL10 hypermorphs suggested that MSL10 may be involved in basal plant defense responses. To test this idea, we syringe-inoculated plants with a mutant strain of Pto DC3000, hrpL. This mutant strain lacks the HrpL transcription factor that controls the expression of type III secretion system genes required for effector secretion, cannot suppress basal defense, and therefore, does not grow to high levels in WT Col-0 plants (Zwiesler-Vollick et al. 2002). When inoculated with Pto DC3000 hrpL mutant bacteria, none of the lines showed apparent differences in viable bacterial counts (Fig. 6B). In addition,

A
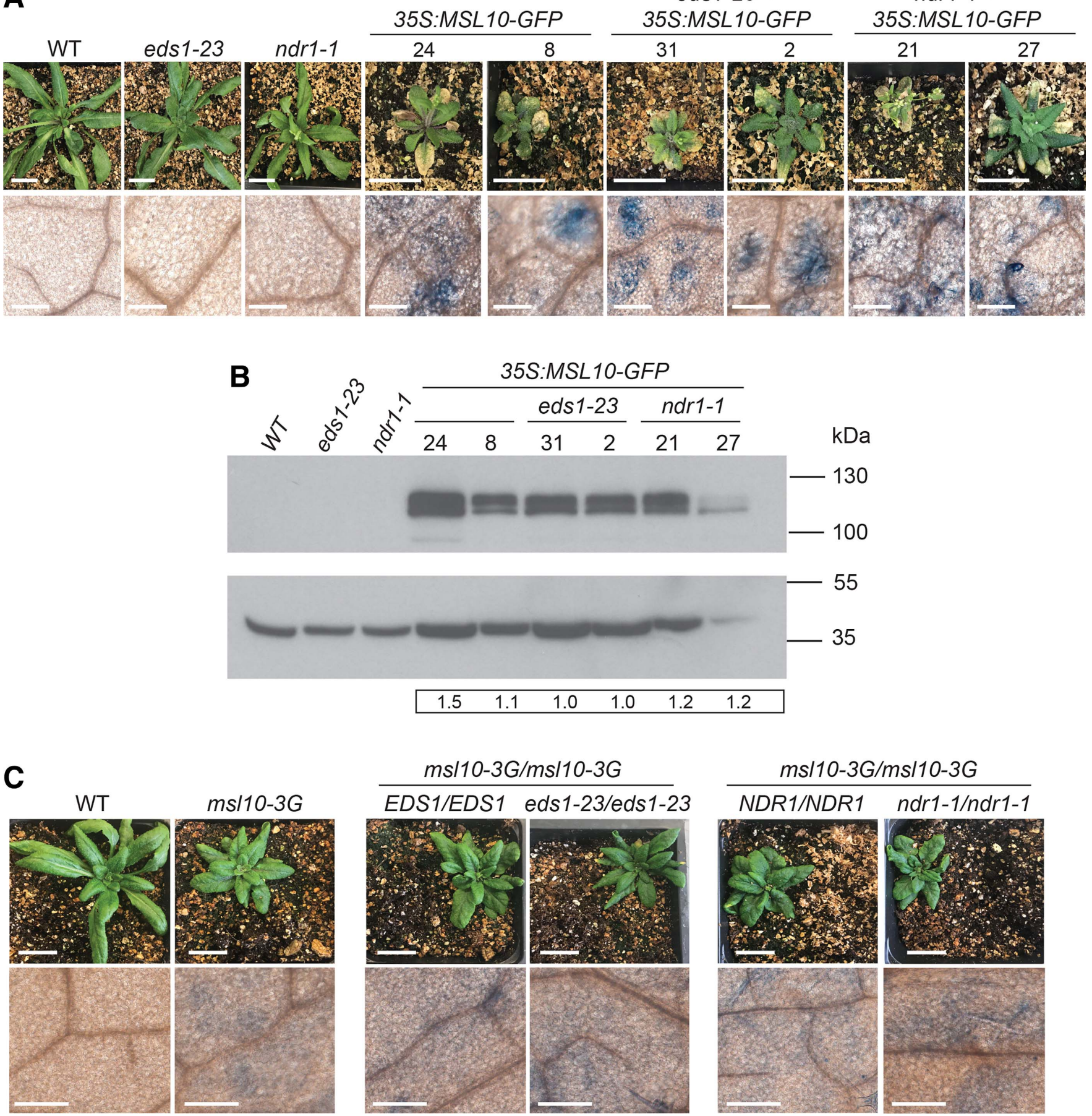

Fig. 4. Disruption of EDS1 or NDR1 fails to suppress phenotypes associated with MSL10 hypermorphs. A, Top row, five-week-old T1 plants grown side-by-side in $24 \mathrm{~h}$ of light at $21^{\circ} \mathrm{C}$. Bars $=2 \mathrm{~cm}$. Bottom row, rosette leaves from the same plants stained with trypan blue to visualize dead cells. Bars $=200 \mu \mathrm{m}$. B, Immunoblot of protein extracts from leaf tissue of T1 lines. Relative MSL10-GFP levels (normalized to tubulin) are shown at the bottom of each lane; replicates and statistics are shown in Supplementary Table S2. C, msl10-3G siblings segregating eds 1-23 or $n d r 1-1$ alleles. Top row, four-week-old plants grown as in A. Bars $=2 \mathrm{~cm}$. Bottom row, dead cells in rosette leaves visualized by trypan blue staining. Bars $=200 \mu \mathrm{m}$. 
we tested the resistance of these lines to avirulent Pseudomonas syringae expressing two well-characterized effectors, Pto DC3000 avrRpt2 and Pto DC3000 avrRpml (Mackey et al. 2003, 2002). We found that MSL10-GFP overexpression lines exhibited enhanced resistance to Pto avrRpt2 (Fig. 6C) and all three hypermorphs exhibited enhanced resistance to Pto avrRpml (Fig. 6D), as compared with WT plants. However, msl10-1 mutants and MSL10g ${ }^{7 D}$ lines were indistinguishable from the WT in these assays. In summary, overactive MSL10 alleles conferred reduced susceptibility to Pto DC3000, Pto avrRpt2, and Pto avrRpm1, but not to Pto DC3000 hrpL. Taken together, these data suggest that MSL10 hypermorphs may act as an autoimmune mutant.

\section{MSL10 is required for normal PATHOGENESIS-RELATED} $1(P R 1)$ induction in response to Pseudomonas infection.

The ectopic cell death observed in autoimmune mutants is often accompanied by constitutive upregulation of defenserelated genes like PRI (Li et al. 2010; Wang et al. 2017; Xu et al. 2015). To investigate whether the same is true of MSL10 hypermorphs, a time-course experiment was performed to evaluate $P R 1$ transcript accumulation in response to Pto DC3000 infection. We found that basal levels of $P R 1$ transcripts were the same in all lines tested. However, the kinetics of induction was different. In WT plants, increased levels of $P R I$ transcripts were detected by $6 \mathrm{~h}$ and continued to increase at the 12- and 24-h timepoints (Fig. 7A). PRI transcript levels also increased after infection in msl10-1 mutants, but the increase was not observable until $12 \mathrm{~h}$ after treatment. On the other hand, $P R I$ expression in the msllo-3G mutant (approximately 18 to 45 -fold) and in MSL10-GFP overexpression lines (approximately 24 to 57 -fold)
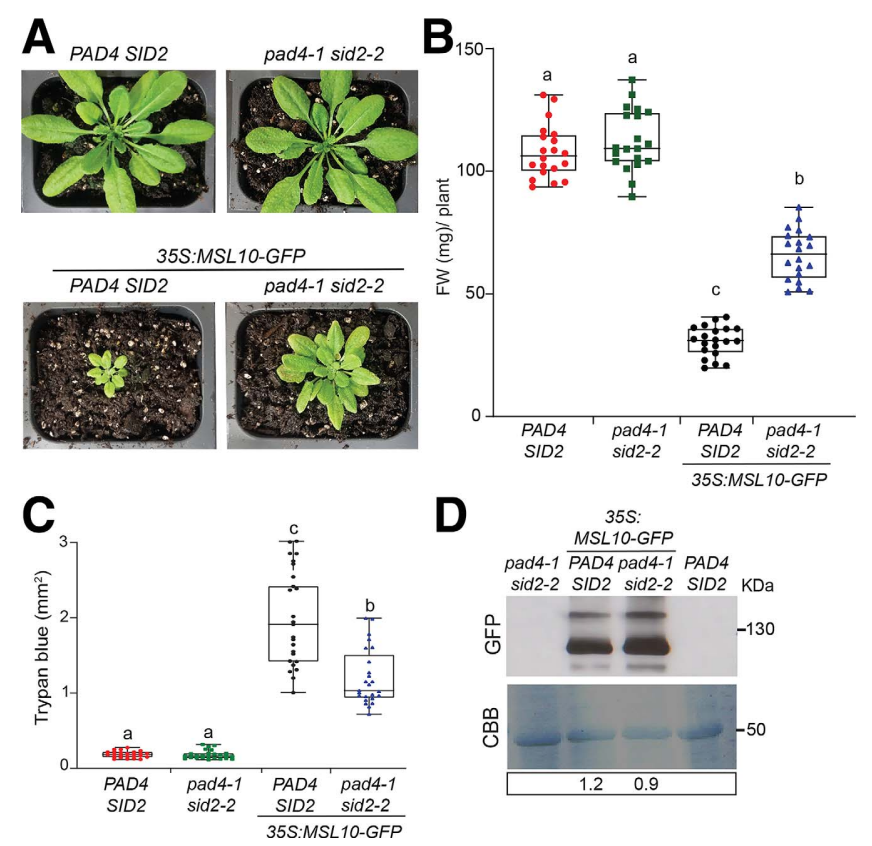

Fig. 5. PAD4 and SID2 are partially required for the phenotypes associated with overexpression of MSL10-GFP. A, Four-week-old plants grown side-by-side in $24 \mathrm{~h}$ of light at $21^{\circ} \mathrm{C}$. B, Average fresh weight (FW) of rosettes grown as in A. C, Ectopic cell death indicated by trypan blue staining in rosette leaves. D, Immunoblot of MSL10-GFP protein levels from three-week old rosette leaves grown as in A. Relative MSL10-GFP levels (normalized to RuBisCO) are shown at the bottom of each lane; replicates and statistics are shown in Supplementary Table $\mathrm{S} 2$. In $\mathrm{B}$ and $\mathrm{C}$, the mean and standard deviation of three independent trials, eight to ten leaves each, are presented, and different letters indicate significant differences, as determined by two-way analysis of variance followed by Tukey's post hoc test $(P<0.05)$. was higher than the WT (approximately five- to 15 -fold) as early as $6 \mathrm{~h}$ after Pto DC3000 infection. At all timepoints tested, plants expressing phospho-mimetic 35S::MSL10 ${ }^{4 D}-G F P$ and MSL10g complemented lines displayed similar $P R I$ expression kinetics as WT plants. We did observe small increases in $P R l$ expression at later timepoints in all genotypes in response to mock infection. This may be attributed to mechanical or osmotic stress resulting from syringe-infiltration (Chandrashekar et al. 2018). Thus, MSL10 positively influences PRI induction after Pto DC3000 infection.

\section{$M S L 10$ is required for normal basal defense, rapid $P R I$ induction, and full stomatal closure in response to Pto DC3000 coronatine-deficient $\left(\mathrm{COR}^{-}\right)$mutant.}

The observation that msl10-1 mutants showed a delayed and attenuated induction of $P R 1$ led us to investigate the role of MSL10 in responding to Pto infection under sensitized conditions. Under natural conditions, the Pseudomonas pathogen enters plants either through wounds or natural openings like stomata and hydathodes (Melotto et al. 2008). Syringe-infiltration directly delivers the bacteria into the apoplast, bypassing these natural entry mechanisms. To assess bacterial growth under more realistic conditions, we spray-inoculated plants with Pto DC3000. As with syringe-infiltration, $m s l 10-3 G$ mutants displayed heightened resistance to Pto DC3000 compared with WT plants, while msl10-1 mutants and the MSL1Og line were indistinguishable from the WT. Coronatine-deficient $\left(\mathrm{COR}^{-}\right)$bacterial mutants have severely compromised virulence when inoculated onto the leaf surface and are useful to characterize mutants with slightly weakened defense responses (Geng et al. 2014). When plants were spray-inoculated with a Pto DC $3000 \mathrm{COR}^{-}$mutant (Brooks et al. 2004), msll0-3G mutants again displayed enhanced resistance compared with the WT at 2 or 3 days after infection (Fig. 7B). Importantly, when using this weaker pathogen and spray-inoculation, msl10-1 showed reduced resistance compared with WT plants at both timepoints. We also observed a similar profile of $P R I$ induction in response to infection with the Pto DC3000 COR ${ }^{-}$mutant strain. MSL10 hypermorphs exhibited higher levels of $P R l$ transcripts, and msl10-1 mutants displayed a delayed and reduced induction of $P R 1$ transcripts (Fig. 7C). These results indicate that MSL10 is required for normal levels of basal defense or innate immunity when presented with modest pathogenic challenges.

As Pto $\mathrm{COR}^{-}$strains are unable to inhibit stomatal closure and early PTI-mediated basal defense responses (Melotto et al. 2006), we hypothesized that the increased susceptibility in msl10-1 mutants might be related to defects in stomatal closure. To test this hypothesis, we measured stomatal aperture from the leaf epidermis of WT, msl10-1, MSL10g, and msl10-3G lines exposed to the Pto DC3000 $\mathrm{COR}^{-}$mutant. WT leaves sprayed with Pto DC3000 briefly closed, then reopened, their stomates (Fig. 7D, left), while the stomates of WT leaves spray-inoculated with the Pto DC3000 $\mathrm{COR}^{-}$mutant closed and did not open again (Fig. 7D, right). All genotypes tested behaved similarly when spray-inoculated with DC3000. However, in response to the Pto DC $3000 \mathrm{COR}^{-}$mutant, the stomates of msllo-1 mutant were significantly more open than all the other genotypes both at 1 and at $4 \mathrm{~h}$ after infection. To determine the specificity of this defect, plants were treated with abscisic acid (ABA), which is known to induce rapid closure (Kim et al. 2010). ABA treatment efficiently produced stomatal closing in all genotypes after $2 \mathrm{~h}$ of ABA incubation, establishing that there is no generic defect in the ability of msl10-1 stomates to close (Fig. 7E). Taken together, these results suggest that MSL10 is required for a robust and rapid response to pathogen invasion and its absence leads to delayed signaling, slower stomatal closure, and increased susceptibility. 


\section{DISCUSSION}

Considerable progress has been made in identifying and characterizing plant receptors involved in detecting bacterial effectors and MAMPs, but less is known about noncanonical players involved in plant defense. Here, we investigated the role of the mechanosensitive ion channel MSL10 in plant immunity. We found that growth at an elevated temperature, loss of the SGT1/ RAR1/HSP90 chaperone complex, or disruption of SA biosynthesis fully or partially alleviated all the phenotypes triggered by
MSL10 hypermorphic alleles that we tested. These phenotypes, most of which are associated with enhanced basal defenses, included dwarfing, ectopic cell death, hyperaccumulation of ROS, and a characteristic gene expression profile (Figs. 1, 2, 3, and 5; Supplementary Figs. S1, S2, and S3). These results suggested that MSL10 hypermorphs are similar to autoimmune mutants. However, the NLR signal transducers EDS1 and NDR1 were not required (Fig. 6). MSL10 hypermorphs exhibited enhanced disease resistance against both virulent and avirulent strains of Pseudomonas syringe but not hrpL (Fig. 6), and msllo
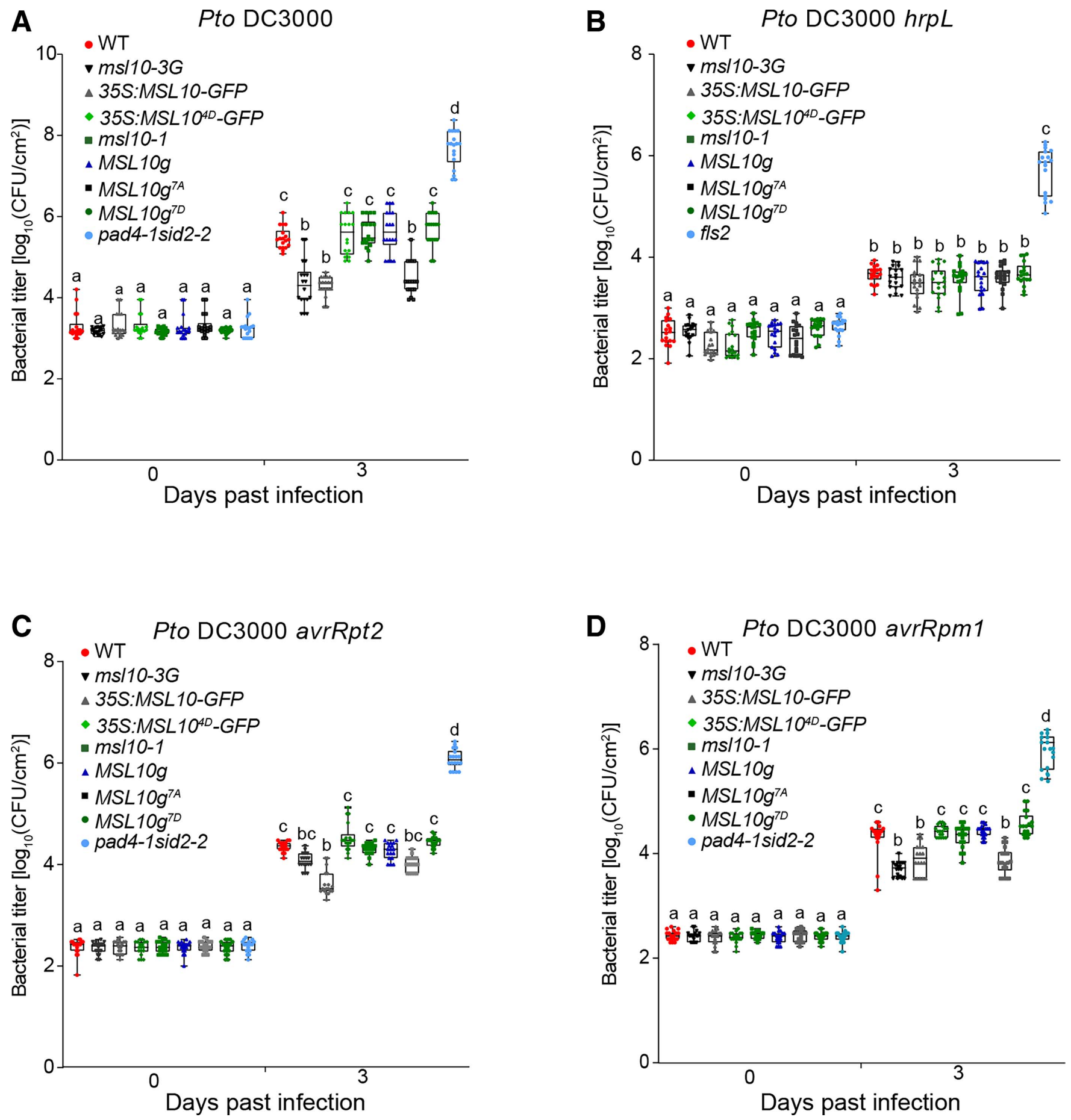

Fig. 6. MSL10 hypermorphs confer reduced susceptibility to Pseudomonas syringae. A to D, Bacterial growth in leaves from plants grown for 5 weeks side-by-side on soil at $28^{\circ} \mathrm{C}$ under a 10-h-light amd 14-h-dark regime and then transferred to $21^{\circ} \mathrm{C}$ for 1 day before syringe inoculation. Means and standard deviation from three independent trials, each with six leaf extracts containing two leaf discs per genotype are presented. Different letters indicate a significant difference as determined by two-way analysis of variance followed by Tukey's post hoc test $(P<0.05)$. 
null mutants showed increased susceptibility to infection by $\mathrm{COR}^{-}$Pto (Fig. 7). We also found that MSL10 promotes precocious $P R l$ induction and is required for normal stomatal closure in response to infection by a Pto DC3000 $\mathrm{COR}^{-}$mutant (Fig. 7).

\section{MSL10 hypermorphs compared with lesion mimic and autoimmune mutants.}

MSL10 hypermorphs strongly resemble a category of mutants called LMMs. LMMs display spontaneous cell death in the absence of any pathogenic infection, mechanical stress, or abiotic stress (Bruggeman et al. 2015; Moeder and Yoshioka 2008). Like MSL10 hypermorphs, LMMs often share other phenotypes, including dwarfing and the constitutive activation of defense responses. Also similar to MSL10 hypermorphs, the phenotypes of some LMMs are temperature-sensitive (Huang et al. 2010; Yang and Hua 2004; Yang et al. 2010). High temperatures suppress immune responses through multiple mechanisms, including resistance $(R)$-gene mediated resistance (Hua 2013) and SA production (Huot et al. 2017), and are known to affect MS ion channel activity (Ding and Pickard 1993). As a result, future work will be needed to determine the mechanism by which temperature affects the phenotypes of MSL10 hypermorphs. Some LMMs are autoimmune mutants in that their phenotypes result from the loss of repression of pathogen responses (Chakraborty et al. 2018; van Wersch et al. 2016). Autoimmune effects can result from the overactivation of PRRs and NLR proteins, the loss of negative regulators of NLRs, and the disruption of NLRguardee interactions and mis-regulation of SA biosynthesis, either singly or in combination. In this study, we provide evidence that the LMM-like phenotypes exhibited by MSL10 hypermorphs are due to the induction of autoimmune responses (discussed below). However, unlike canonical and known autoimmune mutants, MSL10 hypermorphs did not exhibit increased basal expression of the PRl gene (Fig. 7A) (Mauch-Mani et al. 2017).

\section{MSLIO and $R$ gene-mediated immunity.}

The SGT1b/RAR1/HSP90 cochaperone complex is known to function as an integral component of ETI (van Wersch et al. 2020). Silencing of SGT1/RAR1/HSP90 components alleviates autoimmune responses in several autoimmune mutants. For example, SGT1b is a positive regulator of the autoimmune response displayed by chs3 mutants (Xu et al. 2015), HSP90.3 is required for the constitutive activation of defense response in the saull-1 mutant (Liang et al. 2020), and topp4-1 autoimmune phenotypes require RAR1 and HSP90.2 (Yan et al. 2019). Similarly, the spontaneous cell death and hyperaccumulation of ROS exhibited by plants overexpressing MSL10-GFP required $S G T 1 b, R A R 1$, and HSP9O in both tobacco and Arabidopsis (Fig. 3; Supplementary Figs. S2 and S3).

Taken together, these data suggest that MSL10 acts upstream of $R$ gene-mediated immune responses. However, most NLRmediated signaling requires either EDS1 or $N D R 1$, and we observed that disruption of EDSI and NDRI did not alleviate the autoimmune-like phenotypes associated with MSL10 hypermorphs. Furthermore, while autoimmunity can be caused by defects in guardee proteins, msl10 null mutants do not show an autoimmune response under unstressed conditions, indicating that MSL10 is unlikely to function as a guardee. A few scenarios fit the data presented here. MSL10 could function upstream of a pathway that involves R proteins that are EDS1- and NDRI-independent. There is some precedent for such a pathway; the effector Rip1E from Ralstonia solanacearum requires SGT1 but not EDS1 to trigger immunity in N. benthamiana (Sang et al. 2020). Alternatively, MSL10 could function in a pathway that is entirely independent of $R$ genes. For the latter to be the case, the SGT1 complex would have to be involved in an $R$-gene independent function as well, and both HSP90 and SGT1b have been shown to interact with the receptors for plant hormones auxin and jasmonic acid (Wang et al. 2016; Zhang et al. 2015). In summary, there are several ways in which MSL10-based signals could impinge on known pathogen response pathways; additional experiments will be needed to distinguish them.

\section{MS ion channels in pathogen perception.}

Cation fluxes are immediate and essential parts of the host immune response (Moeder et al. 2019), and it was recently reported that the OSCA1 mechanosensitive cation channel is required for defense-induced stomatal closure (Thor et al. 2020). While MSL10 is unlikely to transport calcium directly (Maksaev and Haswell 2012), the release of anions through MSL10 could depolarize the plasma membrane, thereby indirectly activating calcium channels (Guerringue et al. 2018). Indeed, MSL10 is closely associated with and required for the cytoplasmic calcium transient associated with cell swelling (Basu and Haswell 2020). However, the ability to trigger dwarfing and programmed cell death may be triggered independently of ion flux through MSL10 (Maksaev et al. 2018; Veley et al. 2014). Thus, it is possible that MSL10 serves as a sensor of membrane integrity that is triggered by changes in membrane tension resulting from Pseudomonas infection, either due to the insertion or assembly of the type III secretion apparatus within the plasma membrane or indirectly to events triggered by cytoplasmic effectors such as watersoaking (though water-soaking is not seen with avirulent strains [Xin et al. 2016]). Activation of MSL10 could then lead to calcium transients or to nonconducting interactions with components of $R$ gene-mediated immunity, eventually leading to one or both $P R 1$ induction and stomatal closure. Interestingly, the putative MS ion channel MSL4, a close homolog of MSL10, interacts with the defense regulator ACD6 and is required for PRR-mediated basal immunity responses (Zhang et al. 2017) and AtPIEZO1 is required for long distance virus translocation (Zhang et al. 2019). Taken together, these results suggest that MS ion channels play diverse, yet-to-be-discovered roles in plant defense.

\section{MATERIALS AND METHODS}

Plant lines and growth conditions.

Arabidopsis thaliana plants used in this study were of the Col-0 ecotype. The following mutants were used: sid2-2 (Wildermuth et al. 2001), pad4-1 (Jirage et al. 1999), eds1-23 (SALK_057149 [Song 2016]), rarl-21 (Tornero et al. 2002), sgt1b-2 (GABI_857A04 [Zhang et al. 2015]), sgtlb-1 (SALK_026606), ndrl-1 (Century et al. 1997), hsp90.1-1 (SALK 007614 [Takahashi et al. 2003]), fls2 (SALK_141277 [Guo et al. 2014]), msl10-1 (SALK_076254), $m s l 10-3 G$ (Basu et al. 2020; Zou et al. 2016), and msl9-1 (SALK_114626 [Haswell et al. 2008]). In most experiments, plants were grown on soil at $21^{\circ} \mathrm{C}$ under a 24-h light regime (approximately $120 \mu \mathrm{mol} \mathrm{m} \mathrm{s}^{-2}$ ). For experiments done at elevated temperature, plants were grown on soil at high temperatures that ranged from 28 to $30^{\circ} \mathrm{C}$ with 24-h light. For bacterial infection assays and stomatal aperture measurements, plants were grown at $21^{\circ} \mathrm{C}$ under a 24-h light regime for 10 days, until the seedling germinated, followed by $28^{\circ} \mathrm{C}$ under short-day conditions ( $10 \mathrm{~h}$ of light and $14 \mathrm{~h}$ of dark) for 5 weeks. Plants were then acclimatized for $24 \mathrm{~h}$ at $21^{\circ} \mathrm{C}$ in short-day conditions before subjecting them to bacterial infection. The MSL10-GFP overexpression lines (lines 7-1, 12-3, and 15-2) and MSL10g, MSL10g ${ }^{7 A}$, and MSLIOg $^{7 D}$ plant lines are described in earlier studies (Basu et al. 2020; Veley et al. 2014).

\section{Generation of transgenic lines.}

pENTR-MSL10 (Haswell et al. 2008) was introduced into the pEarleyGate destination binary vector pEG103 (Earley et al. 2006) using LR clonase. The resulting 35S::MSL10-GFP construct was 
A

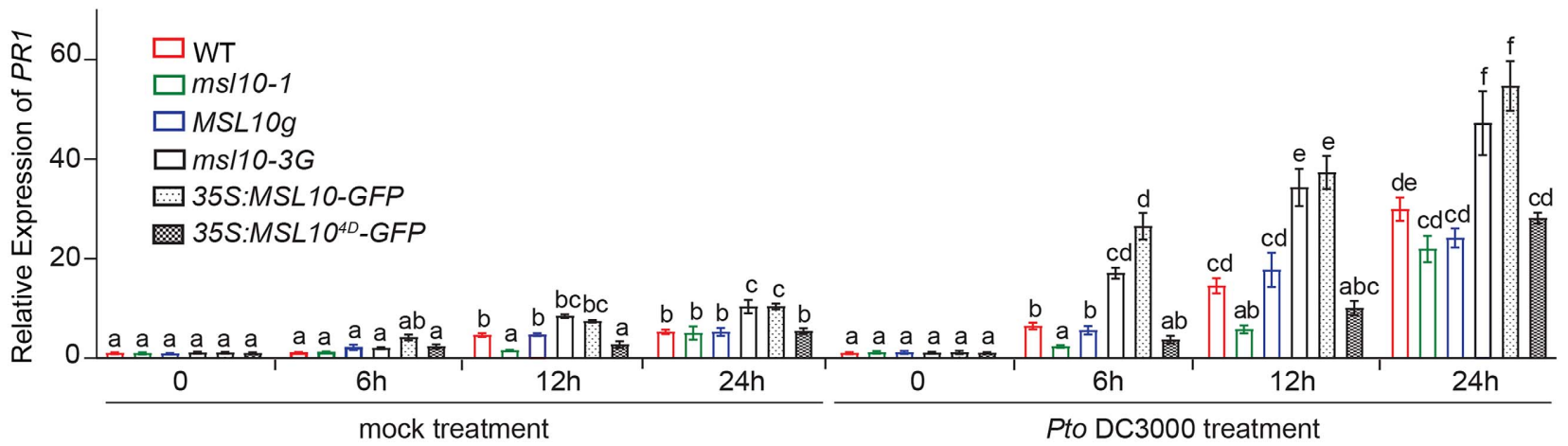

B
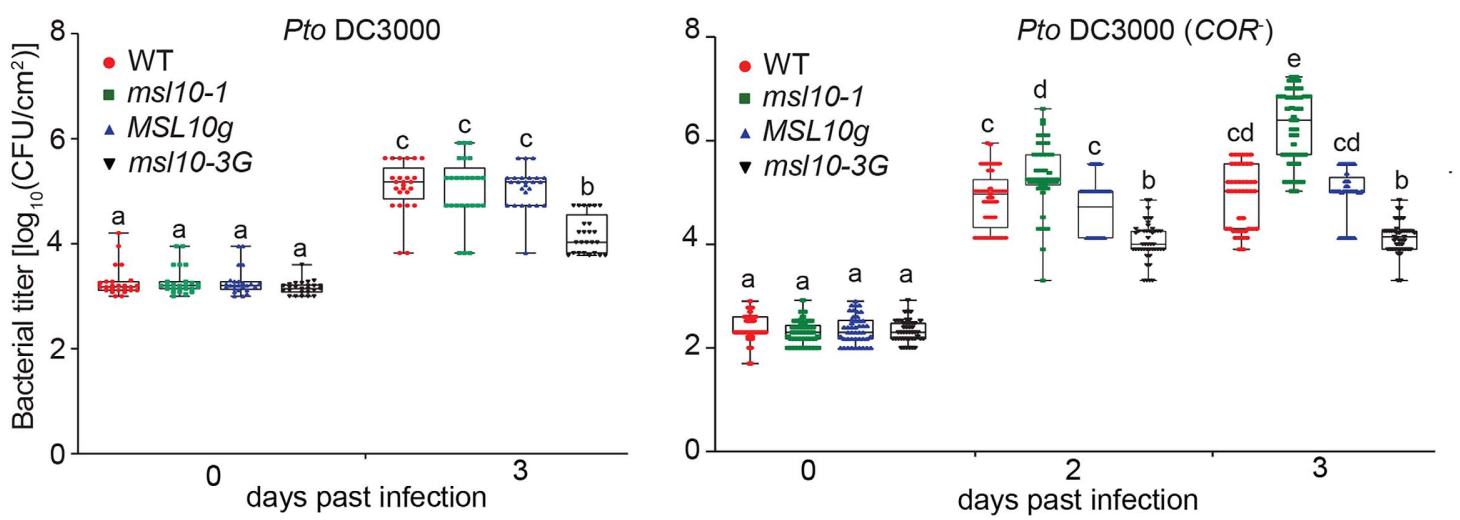

C
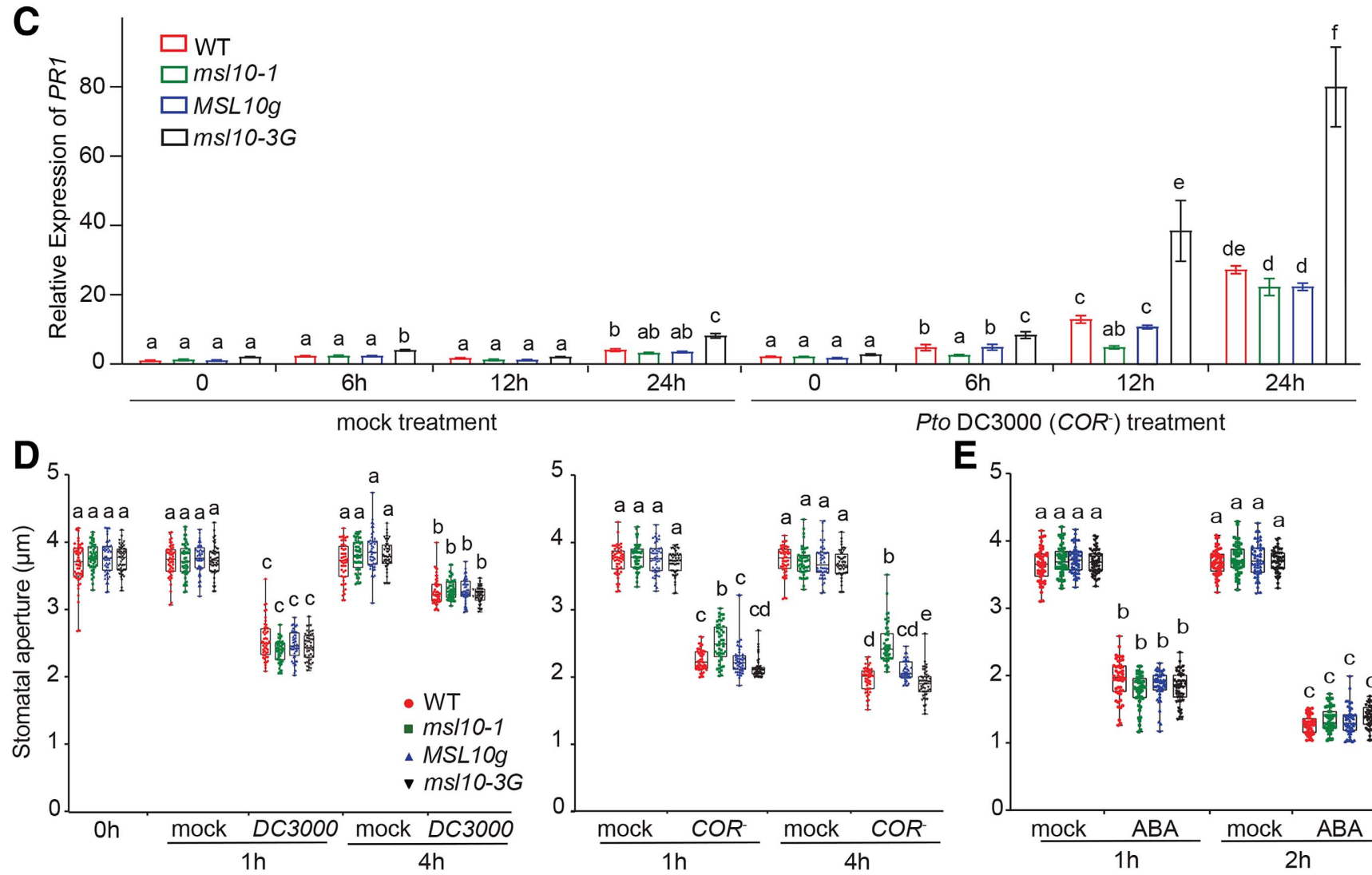

$\mathbf{E}_{5}$

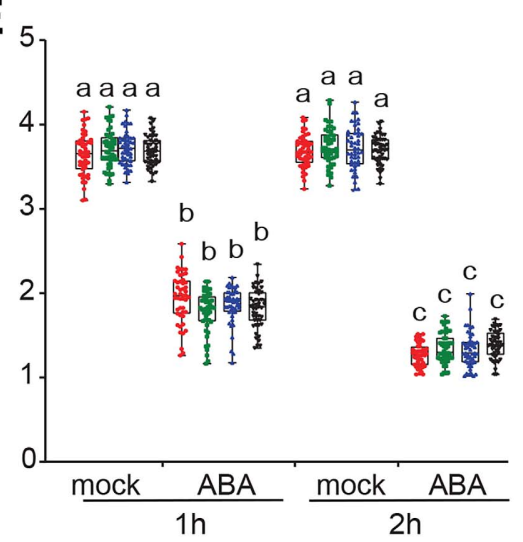

Fig. 7. MSL10 modulates the normal induction of PR1, susceptibility to the Pto DC3000 coronatine-deficient (COR $\left.{ }^{-}\right)$mutant, and stomatal closure. A, PR1 transcript abundance relative to the wild type (WT). RNA was isolated from plants grown and was syringe-inoculated with Pto DC3000. B, Bacterial growth in leaves after spray-inoculation with the Pto DC3000 COR ${ }^{-}$mutant. The means and standard deviation (SD) from five independent trials, each with five to nine leaf extracts, are shown. Each extract contained two leaf discs. C, PRl transcript abundance relative to WT, performed as in A, except that plants were spray-inoculated with the Pto DC3000 COR ${ }^{-}$mutant. D and E, Stomatal aperture measurements. Fully expanded, healthy leaves from 5-week-old plants were immersed in a suspension of Pto DC3000 or the Pto DC3000 COR ${ }^{-}$mutant or $10 \mu \mathrm{M}$ abscisic acid (ABA), and stomatal apertures were measured at the indicated timepoints. Means and SD from three independent trials, each with 16 apertures, are shown. Different letters indicate a significant difference as determined by two-way analysis of variance followed by Tukey's post hoc test $(P<0.05)$. CFU $=$ colony-forming units; mock $=10 \mathrm{mM} \mathrm{MgCl}$. 
transformed into Col-0 (WT), sgt1b, rarl-21, hsp90.1-1, pad41sid2-2, eds1-23, or ndr1-1 mutant backgrounds by Agrobacterium tumefaciens (GV3101)-mediated floral dipping (Clough and Bent 1998). Transgenic plants were selected on soil by spraying with $200 \mathrm{mg}$ of Basta per liter (Finale Herbicide, Southern States Farm Supply), followed by segregation analysis and selection of homozygous transgenic lines with single insertion of transgene on Murashige-Skoog plates supplemented with $20 \mathrm{mg}$ of Basta per liter. Sequences of the primers used for genotyping transgenes or the mutant background are listed in Supplementary Table S1. Since transgene expression in a knock-out mutant background relative to the transgene expression in the WT plant does not involve identical genetic background, it is difficult to compare phenotypes among the transgenic plants. To eliminate such issues, we first introduced the transgene into the knock-out mutant line and then crossed the T1 transgenic line with the WT Col-0 line. Segregating homozygous F2 siblings with identical genetic backgrounds were used for comparison. Plants with the msl10-3G allele were crossed to eds $1-23$ and $n r d r l-1$ plants. F2 progeny homozygous for the $m s l 10-3 G$ allele were identified by genotyping, and comparisons were made between those F2 siblings homozygous for WT or mutant eds1-23 and nrdr1-1 alleles.

\section{Gene expression analysis.}

Quantitative reverse-transcription PCR (qRT-PCR) was performed as described previously (Basu et al. 2020), with minor modifications. In most experiments, total RNA was isolated from the rosette leaves (5th and 9th) of healthy 3-week-old plants using the RNeasy plant mini kit (Qiagen) including DNase I treatment. Rosette leaves from five-to-six-week-old plants were used for RNA extraction for transcript analysis in response to bacterial infection. Reverse transcription was performed using $2 \mu \mathrm{g}$ of total RNA and oligo(dT) $)_{20}$ primers with M-MLV Reverse Transcriptase (Promega). All results shown include data from three independent experiments; for each treatment three technical replicates were performed for each of three independent experiments. Expression levels were normalized to the geometric mean of two reference genes, UBQ5 and EFla. Finally, the relative abundance of transcripts was calculated using the $2^{-\Delta \Delta C t}$ method (Livak and Schmittgen 2001). Semiquantitative RT-PCR was performed as described by Veley et al. (2014). Sequences of the primers used are listed in Supplementary Table S1.

\section{Quantification of ROS in tissue extracts.}

$\mathrm{H}_{2} \mathrm{O}_{2}$ levels in leaf extracts were measured using the Amplex red hydrogen peroxide/peroxidase assay kit (Molecular Probes, Invitrogen) (Basu et al. 2020). Three to five independent experiments were used for each condition at each time interval. The leaves were weighed, frozen, and homogenized in phosphate buffer. Homogenates were centrifuged at $10,000 \times g$ for $10 \mathrm{~min}$ at $4{ }^{\circ} \mathrm{C}$ and the supernatant was used in the Amplex red assay according to manufacturer instructions. Samples were measured with a 96-well microplate reader (Infinite 200 PRO; Tecan) using 530- and 590-nm excitation and emission filters. Fluorescence reads were then normalized to the leaf weight. Superoxide anion radical accumulation was detected by nitroblue tetrazolium chloride (NBT) (Sigma) as described previously (Basu et al. 2020), with some modifications. The 5th or 7 th leaf was weighed and stained with freshly made NBT solution $(1.0 \mathrm{mg}$ of NBT per milliliter in $10 \mathrm{mM} \mathrm{NaN}_{3}$ and $10 \mathrm{mM}$ phosphate buffer, $\mathrm{pH}$ 7.5) for $1 \mathrm{~h}$. NBT-stained samples were then ground and were used to quantify the generation of formazan, by spectrophotometric analysis at $700 \mathrm{~nm}$, using a 96-well microplate reader (Infinite 200 PRO) in the case of data for MSL10g lines with lesions, whereas MSL10 overexpression lines were all analyzed using BioTek PowerWave XS2 microplate spectrophotometer (BioTek). Absorbance reads were then normalized to the leaf weight.

\section{Quantification of cell death.}

Cell death was visualized in leaves of three- to five-week-old soil-grown Arabidopsis plants using trypan blue staining. Whole plant images of MSL10 overexpression lines were obtained with an Olympus SZx7 Stereomicroscope with DP71 digital camera and fitted with DFPL $0.5 \times-4$ objective, while trypan blue-stained lesions were imaged using a BX53 Olympus microscope with DP80 camera digital camera fitted with a UPlanFL N 10x/0.30 objective. The size of trypan blue-stained regions was quantified using ImageJ software as described (Fernández-Bautista et al. 2016; Basu et al. 2020). Cell death in tobacco leaves was determined by staining with FDA $(500 \mu \mathrm{g} / \mathrm{ml})$ and PI $(1.25 \mu \mathrm{g} / \mathrm{ml})$ for $15 \mathrm{~min}$ as described by Veley et al. (2014). The percentage of dead cells was calculated from randomly selected fields from at least three leaves per infiltration.

\section{Genotyping.}

DNA was extracted by grinding tissue in extraction buffer (200 mM Tris- $\mathrm{mCl}, \mathrm{pH} 7.5,250 \mathrm{mM} \mathrm{NaCl}, 250 \mathrm{mM}$ EDTA, $0.5 \%$ sodium dodecyl sulfate [SDS]) and precipitating with an equal volume of isopropanol. PCR-based genotyping of msllo$3 G$, msllo- 1 , and $m s l 9-1$ alleles was performed as described by Haswell et al. (2008) and Basu et al. (2020).

\section{Immunodetection.}

Total proteins were extracted from leaf samples as described previously (Basu et al. 2020). Nonchlorotic leaves of 3- to 5-week-old transgenic Arabidopsis plants expressing MSL10-GFP or $N$. benthamiana leaves 1 week after infiltration with MSL10GFP were collected. Tissue was homogenized in $2 \times$ sample buffer followed by centrifugation at $10,000 \times g$ for $5 \mathrm{~min}$. The supernatant was resolved by $10 \%$ SDS-polyacrylamide gel electrophoresis and was transferred to polyvinylidene difluoride (PVDF) membranes (Millipore) for $16 \mathrm{~h}$ at $100 \mathrm{~mA}$. Transferred proteins were probed with anti-GFP (1:5,000 dilution) (Takara Bio) or anti-tubulin (1:20,000 dilution) (Sigma) as primary antibodies, with incubation for overnight or $2 \mathrm{~h}$, respectively. In some cases, equal loading was demonstrated by staining the PVDF membrane with Coomassie brilliant blue R 250 (Sigma) post-immunodetection. Immunodetection was performed by incubating the immunoblot for $2 \mathrm{~h}$ with anti-mouse immunoglobulin $G$ conjugated with horseradish peroxidase $(1: 10,000$ dilution) (Millipore). Detection was performed using the SuperSignal West Dura detection kit (Thermo Fisher Scientific). Relative intensities were determined by comparing MSL10-GFP protein band intensity with the reference tubulin band intensity or Coomassie blue-stained RuBisCO at $56 \mathrm{kDa}$, using Image J. The quantification was performed on two replicate immunoblots, each using different plant samples. Statistical analysis was performed using Student's $t$ test, and $P$ values are provided in Supplementary Table S2. None of the experimental MSL10-GFP intensities were significantly different from controls.

\section{BiFC assays.}

Entry vectors containing various truncated versions of the MSL10 coding region were recombined into the binary vector pDEST-VYCE(R)GW or pDEST-VYNE(R)GW (Gehl et al. 2009), which carry the C-terminal or N-terminal fragment of Venus YFP (yellow fluorescent protein), respectively, using LR Clonase. The PCR primers used are listed in Supplementary Table S1. MSL10 was tagged at the C terminus, whereas SGT1b, RAR1, and HSP90.1 were tagged at the $\mathrm{N}$ terminus. For subcloning, the open reading frames (ORFs) of $S G T 1 b, R A R l$, and HSP90.1 were amplified from leaf complementary DNA using CloneAmp HiFi PCR Premix (Clontech) and were cloned into pENTR/D-TOPO (Life Technologies). Next, these ORFs were 
inserted into the BiFC destination vector pDEST-VYNE(R)GW, using the Gateway LR Clonase II enzyme mix (Life Technologies). For MSL10, we used constructs previously generated by Basu et al. (2020). The plasmids were introduced into Agrobacterium sp. strain GV3101 and pairwise combinations were coinfiltrated into four- to six-week-old $N$. benthamiana leaves as described (Waadt and Kudla 2008). To suppress posttranscriptional gene silencing, each construct pair was coinfiltrated with Agrobacterium sp. strain AGL-1 harboring p19 (Senthil-Kumar and Mysore 2014). Infiltrated abaxial leaf areas were examined for YFP signal using a confocal microscope (Olympus Fluoview FV 3000) at 3 to 5 days postinoculation, using excitation at 488 $\mathrm{nm}$ and collecting emission from 495 to 550. The experiments were performed at least three times using different batches of plants; for each independent experiment, three $N$. benthamiana plants were infiltrated.

\section{Split-ubiquitin assay (mbSUS).}

Determination of protein-protein interactions by the mbSUS assay was conducted as described previously (Basu et al. 2020; Lee et al. 2019; Obrdlik et al. 2004). The coding regions of $S G T 1 b, R A R 1$, and HSP90.1 cloned into the BiFC destination vectors described above were used as template for amplification, using universal primers as described by Obrdlik et al. 2004). For MSL10, the construct used was described by Basu et al. (2020). The primers used are listed in Supplementary Table S1. These PCR products were cotransformed with either pMetYCgate or pXNGate21-3HA yeast vectors into THY.AP4 or THY.AP5 yeast strains, respectively. All yeast vectors and strains were obtained from the Arabidopsis Biological Resource Center (ABRC). Strength of interaction was quantified by $\beta$-galactosidase activity assays as described (Zhou et al. 2015).

\section{Pseudomonas infection assays.}

Bacterial strains $P$. syringae $\mathrm{DC} 3000, P$. syringae $\mathrm{COR}^{-}$ (DB29; cmaA cfa6 [Brooks et al. 2004]) and the hrpL mutant (Zwiesler-Vollick et al. 2002) were donated by B. N. Kunkel (Department of Biology, Washington University, St Louis). P. syringae bacterial strains were cultured on King's B $(\mathrm{KB})$ media plates supplemented with rifampicin at $50 \mathrm{mg} \mathrm{ml}^{-1}$ for Pto DC3000 and kanamycin at $50 \mathrm{mg} \mathrm{ml}^{-1}$ for the $P$. syringae pv. tomato $\mathrm{COR}^{-}$mutant. For $P$. syringae DC3000 and hrpL mutant growth assays, syringe-infiltration was performed as described by Liu et al. (2015). Briefly, $10^{5} \mathrm{CFU}$ per milliliter (optical density at $600 \mathrm{~nm}\left[\mathrm{OD}_{600}\right]=0.0002$ ) in $10 \mathrm{mM} \mathrm{MgCl}_{2}$ were injected into the underside of the leaves of 5-week-old plants, using a needleless 1-cc syringe. For the $P$. syringae $\mathrm{COR}^{-}$mutant, spray-inoculation was performed at a bacterial titer of $\mathrm{OD}_{600}=$ 0.2 , which corresponds to the final inoculum concentration of $1 \times 10^{8}$ CFU (Jacob et al. 2017). After the indicated days of infection, leaf discs were obtained from three separate plants belonging to each genotype per bacterial strain tested. Bacterial titer was determined by grinding leaf discs to homogeneity in $10 \mathrm{mM} \mathrm{MgCl}$, using a bead mill, and plating a dilution series onto $\mathrm{KB}$ plates with appropriate selection. Colonies were counted, the number was used to calculate the mean CFU per square centimeter for each treatment, and the values were logtransformed. The log-transformed means from individual biological replicates, as single datapoints, were then combined from three to five independent biological trials and used to calculate the mean and standard error.

\section{VIGS and Agrobacterium-mediated transient assays.}

Plasmids pTRV1 and pTRV2 were used for VIGS assays, as previously described (Siddiqui et al. 2008). Constructs pTRV2:00, pTRV2:NbSGT1, pTRV2:NbRAR1, and pTRV2:LeHSP90 were obtained from the ABRC. The empty vector $p T R V 2: 00$ was used as a negative control. pTRV2-NbPDS (PHYTOENE DESATURASE) was used as a positive control for silencing. All these constructs were transformed into A. tumefaciens strain GV3101. For leaf infiltration, GV3101 harboring pTRV1 or transformed with one of the pTRV2 constructs were mixed at a 1:1 ratio to a final $\mathrm{OD}_{600}$ of 0.5 and were then coinfiltrated into two-week-old $N$. benthamiana leaves. Silencing efficiency was evaluated 9 days after infiltration by performing RT-qPCR analysis. After confirming suppression of $S G T 1, R A R 1$, and $H S P 90$, infiltration of MSL10-GFP, MSL10 ${ }^{4 A}$ $G F P$, and $M S L 10^{4 D}$-GFP constructs was performed to a final $\mathrm{OD}_{600}$ of 0.5 , along with $p 19$ to a final $\mathrm{OD}_{600}$ of 0.3 , as described by Maksaev et al. (2018). Each silencing experiment was repeated three times, and each experiment included at least three different plants.

\section{Stomatal aperture.}

Plants were grown under short-day conditions for five to six weeks. Intact leaves (5th, 7th, or 9th) were used for aperture measurements as described (Eisele et al. 2016). Leaves were exposed to white light for $1 \mathrm{~h}$ while floating (abaxial side touching the solution) in stomatal incubation buffer containing $10 \mathrm{mM}$ MES-KOH, $10 \mathrm{mM} \mathrm{KCl,} 50 \mu \mathrm{M} \mathrm{CaCl}_{2}, \mathrm{pH}$ 6.5. Subsequently, one-half of a leaf was immersed in stomatal incubation buffer with the bacterial suspension at $1 \times 10^{8} \mathrm{CFU} / \mathrm{ml}, \mathrm{OD}_{600}=0.2$ and incubated for $4 \mathrm{~h}$; whereas the other half of the leaf was incubated in water. Abaxial leaf surfaces were imaged, and stomatal apertures were measured with ImageJ, as described (Chitrakar and Melotto 2010). To monitor stomatal closing in response to ABA, leaf discs with pre-opened stomates were exposed to the same buffer supplemented with $10 \mu \mathrm{M}$ ABA for $2 \mathrm{~h}$ under the same conditions used by An et al. (2016). Independent trials of the experiments were done around the same time of the day for each of the independent trials and the treatments to avoid potential rhythmic effects of photoperiod on stomatal aperture.

\section{Confocal microscopy.}

The subcellular localization of MSL10-GFP fusion proteins in epidermal cells of $N$. benthamiana leaves and Arabidopsis, as well as FDA and PI dual-stained tobacco epidermal cells, were visualized using on an inverted FV3000 (Olympus) confocal microscope using a $20 \times$ objective. The percentage of dead cells was quantified as outlined by Veley et al. (2014) and Maksaev et al. (2018). FDA and PI dual-stained epidermal cells were imaged sequentially, using the 488-nm laser to excite FDA and the 561-nm laser to excite PI. Emission was detected between 505 and $525 \mathrm{~nm}$ and between 580 and $660 \mathrm{~nm}$ for FDA and PI, respectively. The setting used for capturing FDA signals was also used for detecting GFP signal.

\section{Statistical analyses.}

Statistical evaluations for all figures were conducted using $\mathrm{R}$ Studio software (RStudio) and GraphPad Prism version 7.0. Statistical differences were analyzed as indicated in the figure legends. Tukey's highly significant difference post hoc test was used to determine statistical significance for balanced data sets. Scheffe's post hoc test was used to determine statistical significance for unbalanced data sets.

\section{Data availability.}

Sequence data from this article can be found in the Arabidopsis Genome Initiative database or GenBank under the following accession numbers: MSL9 (At5g19520), MSL10 (At5g12080), SAG12 (At5g45890), PERX34 (At3g49120), DOX1 (At3g01420),

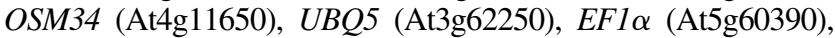
PAD4 (At3g52430), SID2 (Atlg74710), SGT1b (At4g11260), HSP90.1 (At5g52640), RARl (At5g51700), EDS1 (At3g48090), NDRl (At3g20600), and PRl (At2g14610). 


\section{ACKNOWLEDGMENTS}

We thank B. Kunkel (Washington University in St. Louis) for providing pad4 mutant seeds and all Pseudomonas pathovars. All other mutant seeds were obtained from the ABRC.

\section{LITERATURE CITED}

An, Y., Liu, L., Chen, L., and Wang, L. 2016. ALA inhibits ABAinduced stomatal closure via reducing $\mathrm{H}_{2} \mathrm{O}_{2}$ and $\mathrm{Ca}^{2+}$ levels in guard cells. Front. Plant Sci. 7:482.

Bass, R. B., Strop, P., Barclay, M., and Rees, D. C. 2002. Crystal structure of Escherichia coli $\mathrm{MscS}$, a voltage-modulated and mechanosensitive channel. Science 298:1582-1587.

Basu, D., and Haswell, E. S. 2017. Plant mechanosensitive ion channels: An ocean of possibilities. Curr. Opin. Plant Biol. 40:43-48.

Basu, D., and Haswell, E. S. 2020. The mechanosensitive ion channel MSL10 potentiates responses to cell swelling in Arabidopsis seedlings. Curr. Biol. 30:2716-2728.e6.

Basu, D., Shoots, J. M., and Haswell, E. S. 2020. Interactions between the $\mathrm{N}$ - and C-termini of the mechanosensitive ion channel AtMSL10 are consistent with a three-step mechanism for activation. J. Exp. Bot 71:4020-4032.

Baulcombe, D. C. 1999. Fast forward genetics based on virus-induced gene silencing. Curr. Opin. Plant Biol. 2:109-113.

Bi, G., Su, M., Li, N., Liang, Y., Dang, S., Xu, J., Hu, M., Wang, J., Zou, M., Deng, Y., Li, Q., Huang, S., Li, J., Chai, J., He, K., Chen, Y. H., and Zhou, J.-M. 2021. The ZAR1 resistosome is a calciumpermeable channel triggering plant immune signaling. Cell 184:35283541.e12.

Borrelli, G. M., Mazzucotelli, E., Marone, D., Crosatti, C., Michelotti, V., Valè, G., and Mastrangelo, A. M. 2018. Regulation and evolution of NLR genes: A close interconnection for plant immunity. Int. J. Mol. Sci. 19:1662.

Brooks, D. M., Hernández-Guzmán, G., Kloek, A. P., Alarcón-Chaidez, F., Sreedharan, A., Rangaswamy, V., Peñaloza-Vázquez, A., Bender, C. L., and Kunkel, B. N. 2004. Identification and characterization of a well-defined series of coronatine biosynthetic mutants of Pseudomonas syringae pv. tomato DC3000. Mol. Plant-Microbe Interact 17:162-174.

Bruggeman, Q., Raynaud, C., Benhamed, M., and Delarue, M. 2015. To die or not to die? Lessons from lesion mimic mutants. Front. Plant Sci. 6:24

Century, K. S., Holub, E. B., and Staskawicz, B. J. 1995. NDR1, a locus of Arabidopsis thaliana that is required for disease resistance to both a bacterial and a fungal pathogen. Proc. Natl. Acad. Sci. U.S.A. 92 6597-6601.

Century, K. S., Shapiro, A. D., Repetti, P. P., Dahlbeck, D., Holub, E., and Staskawicz, B. J. 1997. NDR1, a pathogen-induced component required for Arabidopsis disease resistance. Science 278:1963-1965.

Chakraborty, J., Ghosh, P., and Das, S. 2018. Autoimmunity in plants. Planta 248:751-767.

Chandrashekar, N., Ali, S., and Grover, A. 2018. Exploring expression patterns of PR-1, PR-2, PR-3, and PR-12 like genes in Arabidopsis thaliana upon Alternaria brassicae inoculation. 3 Biotech. 8:230.

Chiang, Y.-H., and Coaker, G. 2015. Effector triggered immunity: NLR immune perception and downstream defense responses. Arabidopsis Book 13:e0183-12.

Chitrakar, R., and Melotto, M. 2010. Assessing stomatal response to live bacterial cells using whole leaf imaging. J. Vis. Exp. 44:e2185.

Clough, S. J., and Bent, A. F. 1998. Floral dip: A simplified method for Agrobacterium-mediated transformation of Arabidopsis thaliana. Plant J. 16:735-743.

Coppinger, P., Repetti, P. P., Day, B., Dahlbeck, D., Mehlert, A., and Staskawicz, B. J. 2004. Overexpression of the plasma membranelocalized NDR1 protein results in enhanced bacterial disease resistance in Arabidopsis thaliana. Plant J. 40:225-237.

Coutand, C. 2020. The effect of mechanical stress on plant susceptibility to pests: A mini opinion review. Plants Basel 9:632.

Cui, H., Tsuda, K., and Parker, J. E. 2015. Effector-triggered immunity: From pathogen perception to robust defense. Annu. Rev. Plant Biol. 66:487-511.

DeFalco, T. A., and Zipfel, C. 2021. Molecular mechanisms of early plant pattern-triggered immune signaling. Mol. Cell 81:4346.

Deng, Z., Maksaev, G., Schlegel, A. M., Zhang, J., Rau, M., Fitzpatrick, J. A. J., Haswell, E. S., and Yuan, P. 2020. Structural mechanism for gating of a eukaryotic mechanosensitive channel of small conductance. Nat. Commun. 11:3690-3699.
Ding, J. P., and Pickard, B. G. 1993. Modulation of mechanosensitive calcium-selective cation channels by temperature. Plant J. 3:713-720.

Dongus, J. A., and Parker, J. E. 2021. EDS1 signalling: At the nexus of intracellular and surface receptor immunity. Curr. Opin. Plant Biol. 62:102039.

Earley, K. W., Haag, J. R., Pontes, O., Opper, K., Juehne, T., Song, K. and Pikaard, C. S. 2006. Gateway-compatible vectors for plant functional genomics and proteomics. Plant J. 45:616-29.

Eisele, J. F., Fäßler, F., Bürgel, P. F., and Chaban, C. 2016. A rapid and simple method for microscopy-based stomata analyses. PLoS One 11: e0164576.

Engelsdorf, T., Gigli-Bisceglia, N., Veerabagu, M., McKenna, J. F. Vaahtera, L., Augstein, F., Van der Does, D., Zipfel, C., and Hamann, T. 2018. The plant cell wall integrity maintenance and immune signaling systems cooperate to control stress responses in Arabidopsis thaliana. Sci. Signal. 11:eaao3070.

Fernández-Bautista, N., Domínguez-Núñez, J., Moreno, M. M., and Berrocal-Lobo, M. 2016. Plant tissue trypan blue staining during phytopathogen infection. Bio Protoc. 6:e2078.

Gehl, C., Waadt, R., Kudla, J., Mendel, R.-R., and Hänsch, R. 2009. New GATEWAY vectors for high throughput analyses of proteinprotein interactions by bimolecular fluorescence complementation. Mol. Plant 2:1051-1058

Geng, X., Jin, L., Shimada, M., Kim, M. G., and Mackey, D. 2014. The phytotoxin coronatine is a multifunctional component of the virulence armament of Pseudomonas syringae. Planta 240:1149-1165.

Guerringue, Y., Thomine, S., and Frachisse, J.-M. 2018. Sensing and transducing forces in plants with MSL10 and DEK1 mechanosensors. FEBS Lett. 592:1968-1979.

Guo, W., Zuo, Z., Cheng, X., Sun, J., Li, H., Li, L., and Qiu, J.-L. 2014 The chloride channel family gene CLCd negatively regulates pathogen-associated molecular pattern (PAMP)-triggered immunity in Arabidopsis. J. Exp. Bot. 65:1205-1215.

Hammoudi, V., Fokkens, L., Beerens, B., Vlachakis, G., Chatterjee, S., Arroyo-Mateos, M., Wackers, P. F. K., Jonker, M. J., and van den Burg, H. A. 2018. The Arabidopsis SUMO E3 ligase SIZ1 mediates the temperature dependent trade-off between plant immunity and growth. PLoS Genet. 14:e1007157.

Haswell, E. S., Peyronnet, R., Barbier-Brygoo, H., Meyerowitz, E. M., and Frachisse, J.-M. 2008. Two MscS homologs provide mechanosensitive channel activities in the Arabidopsis root. Curr. Biol. 18:730-734.

Hua, J. 2013. Modulation of plant immunity by light, circadian rhythm, and temperature. Curr. Opin. Plant Biol. 16:406-413.

Huang, X., Li, J., Bao, F., Zhang, X., and Yang, S. 2010. A gain-of-function mutation in the Arabidopsis disease resistance gene RPP4 confers sensitivity to low temperature. Plant Physiol. 154:796-809.

Huot, B., Castroverde, C. D. M., Velásquez, A. C., Hubbard, E., Pulman, J. A., Yao, J., Childs, K. L., Tsuda, K., Montgomery, B. L., and He, S. Y. 2017. Dual impact of elevated temperature on plant defence and bacterial virulence in Arabidopsis. Nat. Commun. 8:1808.

Jacob, C., Panchal, S., and Melotto, M. 2017. Surface inoculation and quantification of Pseudomonas syringae population in the Arabidopsis leaf apoplast. Bio Protoc. 7:e1267.

Jirage, D., Tootle, T. L., Reuber, T. L., Frost, L. N., Feys, B. J., Parker, J. E., Ausubel, F. M., and Glazebrook, J. 1999. Arabidopsis thaliana PAD4 encodes a lipase-like gene that is important for salicylic acid signaling. Proc. Natl. Acad. Sci. U.S.A. 96:13583-13588.

Jones, J. D. G., Vance, R. E., and Dangl, J. L. 2016. Intracellular innate immune surveillance devices in plants and animals. Science 354:aaf6395.

Kadota, Y., Shirasu, K., and Guerois, R. 2010. NLR sensors meet at the SGT1-HSP90 crossroad. Trends Biochem. Sci. 35:199-207.

Khan, M., Seto, D., Subramaniam, R., and Desveaux, D. 2018. Oh, the places they'll go! A survey of phytopathogen effectors and their host targets. Plant J. 93:651-663.

Kim, T.-H., Böhmer, M., Hu, H., Nishimura, N., and Schroeder, J. I. 2010 Guard cell signal transduction network: Advances in understanding abscisic acid, $\mathrm{CO}_{2}$, and $\mathrm{Ca}^{2+}$ signaling. Annu. Rev. Plant Biol. 61:561-591.

Knepper, C., Savory, E. A., and Day, B. 2011. Arabidopsis NDR1 is an integrin-like protein with a role in fluid loss and plasma membranecell wall adhesion. Plant Physiol. 156:286-300.

Lee, J. S., Wilson, M. E., Richardson, R. A., and Haswell, E. S. 2019. Genetic and physical interactions between the organellar mechanosensitive ion channel homologs MSL1, MSL2, and MSL3 reveal a role for inter-organellar communication in plant development. Plant Direct 3:e00124

Li, Y., Li, S., Bi, D., Cheng, Y. T., Li, X., and Zhang, Y. 2010. SRFR1 negatively regulates plant NB-LRR resistance protein accumulation to prevent autoimmunity. PLoS Pathog. 6:e1001111. 
Liang, W., Tong, M., and Li, X. 2020. SUSA2 is an F-box protein required for autoimmunity mediated by paired NLRs SOC3-CHS1 and SOC3-TN2. Nat. Commun. 11:5190.

Liu, X., Sun, Y., Kørner, C. J., Du, X., Vollmer, M. E., and PajerowskaMukhtar, K. M. 2015. Bacterial leaf infiltration assay for fine characterization of plant defense responses using the Arabidopsis thaliana-Pseudomonas syringae pathosystem. J. Vis. Exp. 104:e53364.

Liu, Y., Burch-Smith, T., Schiff, M., Feng, S., and Dinesh-Kumar, S. P. 2004. Molecular chaperone Hsp90 associates with resistance protein N and its signaling proteins SGT1 and Rar1 to modulate an innate immune response in plants. J. Biol. Chem. 279:2101-2108.

Livak, K. J., and Schmittgen, T. D. 2001. Analysis of relative gene expression data using real-time quantitative PCR and the $2^{-\Delta \Delta \mathrm{Ct}}$ method. Methods 25:402-408.

Ma, S., Lapin, D., Liu, L., Sun, Y., Song, W., Zhang, X., Logemann, E., Yu, D., Wang, J., Jirschitzka, J., Han, Z., Schulze-Lefert, P., Parker, J. E., and Chai, J. 2020. Direct pathogen-induced assembly of an NLR immune receptor complex to form a holoenzyme. Science 370 : eabe3069.

Mackey, D., Belkhadir, Y., Alonso, J. M., Ecker, J. R., and Dangl, J. L. 2003. Arabidopsis RIN4 is a target of the type III virulence effector AvrRpt2 and modulates RPS2-mediated resistance. Cell 112:379-389.

Mackey, D., Holt, B. F., 3rd, Wiig, A., and Dang1, J. L. 2002. RIN4 interacts with Pseudomonas syringae type III effector molecules and is required for RPM1-mediated resistance in Arabidopsis. Cell 108 743-754.

Maksaev, G., and Haswell, E. S. 2012. MscS-Like10 is a stretchactivated ion channel from Arabidopsis thaliana with a preference for anions. Proc. Natl. Acad. Sci. U.S.A. 109:19015-19020.

Maksaev, G., Shoots, J. M., Ohri, S., and Haswell, E. S. 2018. Nonpolar residues in the presumptive pore-lining helix of mechanosensitive channel MSL10 influence channel behavior and establish a nonconducting function. Plant Direct 2:1-13.

Martin, R., Qi, T., Zhang, H., Liu, F., King, M., Toth, C., Nogales, E., and Staskawicz, B. J. 2020. Structure of the activated ROQ1 resistosome directly recognizing the pathogen effector XopQ. Science 370: eabd9993.

Mauch-Mani, B., Baccelli, I., Luna, E., and Flors, V. 2017. Defense priming: An adaptive part of induced resistance. Annu. Rev. Plant Biol. 68:485-512.

Melotto, M., Underwood, W., and He, S. Y. 2008. Role of stomata in plant innate immunity and foliar bacterial diseases. Annu. Rev. Phytopathol. 46:101-122.

Melotto, M., Underwood, W., Koczan, J., Nomura, K., and He, S. Y. 2006. Plant stomata function in innate immunity against bacterial invasion. Cell 126:969-980.

Moeder, W., Phan, V., and Yoshioka, K. 2019. $\mathrm{Ca}^{2+}$ to the rescue $\mathrm{Ca}^{2+}$ channels and signaling in plant immunity. Plant Sci. 279:19-26.

Moeder, W., and Yoshioka, K. 2008. Lesion mimic mutants: A classical, yet still fundamental approach to study programmed cell death. Plant Signal. Behav. 3:764-767.

Ng, G., Seabolt, S., Zhang, C., Salimian, S., Watkins, T. A., and Lu, H 2011. Genetic dissection of salicylic acid-mediated defense signaling networks in Arabidopsis. Genetics 189:851-859.

Obrdlik, P., El-Bakkoury, M., Hamacher, T., Cappellaro, C., Vilarino, C. Fleischer, C., Ellerbrok, H., Kamuzinzi, R., Ledent, V., Blaudez, D. Sanders, D., Revuelta, J. L., Boles, E., André, B., and Frommer, W. B. 2004. K+ channel interactions detected by a genetic system optimized for systematic studies of membrane protein interactions. Proc. Natl. Acad. Sci. U.S.A. 101:12242-12247.

Peng, Y., Yang, J., Li, X., and Zhang, Y. 2021. Salicylic acid: Biosynthesis and signaling. Annu. Rev. Plant Biol. 72:761-791.

Saijo, Y., Loo, E. P., and Yasuda, S. 2018. Pattern recognition receptors and signaling in plant-microbe interactions. Plant J. 93:592-613.

Sang, Y., Yu, W., Zhuang, H., Wei, Y., Derevnina, L., Yu, G., Luo, J., and Macho, A. P. 2020. Intra-strain Elicitation and Suppression of Plant Immunity by Ralstonia solanacearum Type-III Effectors in Nicotiana benthamiana. Plant Commun. 1:100025.

Saur, I. M. L., Panstruga, R., and Schulze-Lefert, P. 2021. NOD-like receptor-mediated plant immunity: From structure to cell death. Nat. Rev. Immunol. 21:305-318.

Senthil-Kumar, M., and Mysore, K. S. 2014. Tobacco rattle virus-based virus-induced gene silencing in Nicotiana benthamiana. Nat. Prot. 9:1549-1562

Siddiqui, S. A., Sarmiento, C., Truve, E., Lehto, H., and Lehto, K. 2008. Phenotypes and functional effects caused by various viral RNA silencing suppressors in transgenic Nicotiana benthamiana and N. tabacum. Mol. Plant-Microbe Interact. 21:178-187.
Siligardi, G., Zhang, M., and Prodromou, C. 2018. The stoichiometric interaction of the Hsp90-Sgt1-Rar1 complex by CD and SRCD spectroscopy. Front. Mol. Biosci. 4:95.

Song, S.-K. 2016. Misexpression of AtTX12 encoding a toll/interleukin-1 receptor domain induces growth defects and expression of defenserelated genes partially independently of EDS1 in Arabidopsis. BMB Rep. 49:693-698.

Takahashi, A., Casais, C., Ichimura, K., and Shirasu, K. 2003. HSP90 interacts with RAR1 and SGT1 and is essential for RPS2-mediated disease resistance in Arabidopsis. Proc. Natl. Acad. Sci. U.S.A. 100: 11777-11782

Thor, K., Jiang, S., Michard, E., George, J., Scherzer, S., Huang, S., Dindas, J., Derbyshire, P., Leitão, N., DeFalco, T. A., Köster, P., Hunter, K. Kimura, S., Gronnier, J., Stransfeld, L., Kadota, Y., Bücherl, C. A., Charpentier, M., Wrzaczek, M., MacLean, D., Oldroyd, G. E. D. Menke, F. L. H., Roelfsema, M. R. G., Hedrich, R., Feijó, J., and Zipfel, C. 2020. The calcium-permeable channel OSCA1.3 regulates plant stomatal immunity. Nature 585:569-573.

Tornero, P., Merritt, P., Sadanandom, A., Shirasu, K., Innes, R. W., and Dangl, J. L. 2002. RARl and NDRI contribute quantitatively to disease resistance in Arabidopsis, and their relative contributions are dependent on the $R$ gene assayed. Plant Cell 14:1005-1015.

Toruño, T. Y., Stergiopoulos, I., and Coaker, G. 2016. Plant-pathogen effectors: Cellular probes interfering with plant defenses in spatial and temporal manners. Annu. Rev. Phytopathol. 54:419-441.

van Wersch, R., Li, X., and Zhang, Y. 2016. Mighty dwarfs: Arabidopsis autoimmune mutants and their usages in genetic dissection of plant immunity. Front. Plant Sci. 7:1717.

van Wersch, S., Tian, L., Hoy, R., and Li, X. 2020. Plant NLRs: The whistleblowers of plant immunity. Plant Commun. 1:100016.

Veley, K. M., Maksaev, G., Frick, E. M., January, E., Kloepper, S. C., and Haswell, E. S. 2014. Arabidopsis MSL10 has a regulated cell death signaling activity that is separable from its mechanosensitive ion channel activity. Plant Cell 26:3115-3131.

Waadt, R., and Kudla, J. 2008. In planta visualization of protein interactions using bimolecular fluorescence complementation (BiFC). Cold Spring Harb Protoc. 2008:pdb.prot4995

Wang, J., Hu, M., Wang, J., Qi, J., Han, Z., Wang, G., Qi, Y., Wang, H.W., Zhou, J.-M., and Chai, J. 2019. Reconstitution and structure of a plant NLR resistosome conferring immunity. Science 364:eaav5870.

Wang, R., Zhang, Y., Kieffer, M., Yu, H., Kepinski, S., and Estelle, M. 2016. HSP90 regulates temperature-dependent seedling growth in Arabidopsis by stabilizing the auxin co-receptor F-box protein TIR1. Nat. Commun. 7:10269.

Wang, Z., Cui, D., Liu, J., Zhao, J., Liu, C., Xin, W., Li, Y., Liu, N., Ren, D., Tang, D., and Hu, Y. 2017. Arabidopsis ZED1-related kinases mediate the temperature-sensitive intersection of immune response and growth homeostasis. New Phytol. 215:711-724.

Wildermuth, M. C., Dewdney, J., Wu, G., and Ausubel, F. M. 2001. Isochorismate synthase is required to synthesize salicylic acid for plant defence. Nature 414:562-565.

Xin, X.-F., and He, S. Y. 2013. Pseudomonas syringae pv. tomato DC3000: A model pathogen for probing disease susceptibility and hormone signaling in plants. Annu. Rev. Phytopathol. 51:473-498.

Xin, X.-F., Nomura, K., Aung, K., Velásquez, A. C., Yao, J., Boutrot, F., Chang, J. H., Zipfel, C., and He, S. Y. 2016. Bacteria establish an aqueous living space in plants crucial for virulence. Nature 539:524-529.

Xu, F., Zhu, C., Cevik, V., Johnson, K., Liu, Y., Sohn, K., Jones, J. D., Holub, E. B., and Li, X. 2015. Autoimmunity conferred by chs3-2D relies on CSA1, its adjacent TNL-encoding neighbour. Sci. Rep. 5:8792.

Yan, J., Liu, Y., Huang, X., Li, L., Hu, Z., Zhang, J., Qin, Q., Yan, L., He, K., Wang, Y., and Hou, S. 2019. An unreported NB-LRR protein SUT1 is required for the autoimmune response mediated by type one protein phosphatase 4 mutation (topp4-1) in Arabidopsis. Plant J. 100: 357-373.

Yang, H., Shi, Y., Liu, J., Guo, L., Zhang, X., and Yang, S. 2010. A mutant CHS3 protein with TIR-NB-LRR-LIM domains modulates growth, cell death and freezing tolerance in a temperature-dependent manner in Arabidopsis. Plant J. 63:283-296.

Yang, S., and Hua, J. 2004. A haplotype-specific resistance gene regulated by BONZAI1 mediates temperature-dependent growth control in Arabidopsis. Plant Cell 16:1060-1071.

Zhang, X.-C., Millet, Y. A., Cheng, Z., Bush, J., and Ausubel, F. M. 2015. Jasmonate signalling in Arabidopsis involves SGT1b-HSP70HSP90 chaperone complexes. Nat. Plants 1:15049.

Zhang, Z., Tateda, C., Jiang, S.-C., Shrestha, J., Jelenska, J., Speed, D. J., and Greenberg, J. T. 2017. A suite of receptor-like kinases and a putative mechano-sensitive channel are involved in autoimmunity and 
plasma membrane-based defenses in Arabidopsis. Mol. Plant-Microbe Interact 30:150-160.

Zhang, Z., Tong, X., Liu, S.-Y., Chai, L.-X., Zhu, F.-F., Zhang, X.-P., Zou, J.-Z., and Wang, X.-B. 2019. Genetic analysis of a Piezo-like protein suppressing systemic movement of plant viruses in Arabidopsis thaliana. Sci. Rep. 9:3187.

Zhou, J.-M., and Zhang, Y. 2020. Plant immunity: Danger perception and signaling. Cell 181:978-989.

Zhou, X., Welsch, R., Yang, Y., Álvarez, D., Riediger, M., Yuan, H., Fish, T., Liu, J., Thannhauser, T. W., and Li, L. 2015. Arabidopsis OR proteins are the major posttranscriptional regulators of phytoene synthase in controlling carotenoid biosynthesis. Proc. Natl. Acad. Sci. U.S.A. 112:3558-3563.

Zou, Y., Chintamanani, S., He, P., Fukushige, H., Yu, L., Shao, M., Zhu, L., Hildebrand, D. F., Tang, X., and Zhou, J.-M. 2016. A gain-of-function mutation in Msl10 triggers cell death and wound-induced hyperaccumulation of jasmonic acid in Arabidopsis. J. Integr. Plant Biol. 58:600-609.

Zwiesler-Vollick, J., Plovanich-Jones, A. E., Nomura, K., Bandyopadhyay, S., Joardar, V., Kunkel, B. N., and He, S. Y. 2002. Identification of novel hrp-regulated genes through functional genomic analysis of the Pseudomonas syringae pv. tomato DC3000 genome. Mol. Microbiol. 45:1207-1218. 